\title{
Loss of System $\mathrm{x}_{\mathrm{c}}^{-}$Does Not Induce Oxidative Stress But Decreases Extracellular Glutamate in Hippocampus and Influences Spatial Working Memory and Limbic Seizure Susceptibility
}

\author{
Dimitri De Bundel, ${ }^{1 \star}$ Anneleen Schallier, ${ }^{1 \star}$ Ellen Loyens, ${ }^{1}$ Ruani Fernando, ${ }^{2}$ Hirohisa Miyashita, ${ }^{3}$ \\ Joeri Van Liefferinge, ${ }^{1}$ Katia Vermoesen, ${ }^{1}$ Shiro Bannai, ${ }^{3}$ Hideyo Sato,${ }^{3}$ Yvette Michotte, ${ }^{1}$ Ilse Smolders,${ }^{1 *}$ \\ and Ann Massie ${ }^{1^{*}}$ \\ ${ }^{1}$ Department of Pharmaceutical Chemistry and Drug Analysis, Center for Neuroscience, Vrije Universiteit Brussel, 1090 Brussels, Belgium, ${ }^{2}$ Department of \\ Medical Biochemistry and Biophysics, Karolinska Institutet, 17177 Stockholm, Sweden, and ${ }^{3}$ Department of Food and Applied Life Sciences, Faculty of \\ Agriculture, Yamagata University, Tsuruoka, Yamagata 997-8555, Japan
}

System $\mathrm{x}_{\mathrm{c}}^{-}$exchanges intracellular glutamate for extracellular cystine, giving it a potential role in intracellular glutathione synthesis and nonvesicular glutamate release. We report that mice lacking the specific $\mathrm{xCT}$ subunit of system $\mathrm{x}_{\mathrm{c}}^{-}\left(x \mathrm{CT}^{-/-}\right)$do not have a lower hippocampal glutathione content, increased oxidative stress or brain atrophy, nor exacerbated spatial reference memory deficits with aging. Together these results indicate that loss of system $\mathrm{x}_{\mathrm{c}}^{-}$does not induce oxidative stress in vivo. Young $x \mathrm{CT}^{-/-}$mice did however display a spatial working memory deficit. Interestingly, we observed significantly lower extracellular hippocampal glutamate concentrations in $x C T^{-1-}$ mice compared to wild-type littermates. Moreover, intrahippocampal perfusion with system $\mathrm{x}_{\mathrm{c}}^{-}$inhibitors lowered extracellular glutamate, whereas the system $\mathrm{x}_{c}^{-}$activator $N$-acetylcysteine elevated extracellular glutamate in the rat hippocampus. This indicates that system $\mathrm{x}_{\mathrm{c}}^{-}$may be an interesting target for pathologies associated with excessive extracellular glutamate release in the hippocampus. Correspondingly, $\mathrm{xCT}$ deletion in mice elevated the threshold for limbic seizures and abolished the proconvulsive effects of $N$-acetylcysteine. These novel findings sustain that system $\mathrm{x}_{c}^{-}$is an important source of extracellular glutamate in the hippocampus. System $\mathrm{x}_{\mathrm{c}}^{-}$is required for optimal spatial working memory, but its inactivation is clearly beneficial to decrease susceptibility for limbic epileptic seizures.

\section{Introduction}

The cystine/glutamate antiporter, or system $\mathrm{x}_{\mathrm{c}}^{-}$, is a membranebound $\mathrm{Na}^{+}$-independent amino acid transporter that is structurally composed of a heavy chain subunit common to all amino acid transporters, $4 \mathrm{~F} 2$, and a light chain specific subunit, $\mathrm{xCT}$ (Sato et al., 1999). System $x_{c}^{-}$exchanges intracellular glutamate for extracellular cystine, thereby supporting intracellular glutathione (GSH) synthesis as well as nonvesicular glutamate release

Received Oct. 18, 2010; revised Feb. 3, 2011; accepted Feb. 16, 2011.

Author contributions:D.D.B., S.B., H.S., Y.M., I.J.S., and A.M. designed research;D.D.B., A.S., E.L., R.F., H.M., J.V.L., K.V., H.S., I.J.S., and A.M. performed research; D.D.B., A.S., E.L., R.F., H.M., J.V.L., K.V., H.S., Y.M., I.J.S., and A.M. analyzed data; D.D.B., A.S., I.J.S., and A.M. wrote the paper.

This work was supported by grants of the Brussels Capital-Region (Prospective Research for Brussels), Fonds voor Wetenschappelijk Onderzoek FW0-Flanders, the Medical Foundation Queen Elizabeth (GSKE), and the Vrije Universiteit Brussel. A.S. is a research assistant of FWO-Flanders. We acknowledge Mr. G. De Smet and Ms. A. De Smet for excellent technical assistance, as well as Dr. M. Watanabe for providing us with antibodies and Dr. R. Kaminski for his valuable scientific advice concerning the epilepsy models.

${ }^{*}$ D.D.B. and A.S. contributed equally to this work.

${ }^{\ddagger}$ I.S. and A.M. contributed equally to this work.

Correspondence should be addressed to Dr. Ilse Smolders, Laarbeeklaan 103, 1090 Brussels, Belgium. E-mail: ilse.smolders@vub.ac.be.

DOI:10.1523/JNEUROSCI.5465-10.2011

Copyright $@ 2011$ the authors $\quad 0270-6474 / 11 / 315792-12 \$ 15.00 / 0$
(Bannai, 1986). Given this crucial dual role of system $\mathrm{x}_{\mathrm{c}}^{-}$, its potential involvement in neurodegenerative disorders has been investigated previously (Qin et al., 2006; Massie et al., 2008, 2011; Lewerenz and Maher, 2009; Liu et al., 2009; Albrecht et al., 2010; Schallier et al., 2011). Nevertheless, system $\mathrm{x}_{\mathrm{c}}^{-}$was never studied in the context of hippocampus-dependent functions, e.g., spatial working memory or limbic seizure development.

Cystine uptake by system $\mathrm{x}_{\mathrm{c}}^{-}$is critical for providing sufficient intracellular cysteine as substrate for GSH synthesis in various brain cell types in culture (Murphy et al., 1990; Back et al., 1998; Shih et al., 2006). Cultured neurons lose the capacity of cystine uptake via system $\mathrm{x}_{\mathrm{c}}^{-}$during development (Murphy et al., 1990; Sagara et al., 1993; Dringen et al., 1999). Yet, neuronal GSH synthesis is indirectly supported by astrocytic GSH release, its cleavage to cysteinylglycine and cysteine, and neuronal cysteine uptake through glutamate transporter EAAC1 (Dringen et al., 1999; Shanker and Aschner, 2001; Chen and Swanson, 2003). The in vivo role of system $\mathrm{x}_{\mathrm{c}}^{-}$in maintaining GSH synthesis and redox balance in hippocampus, however, remains elusive.

Since import of cystine is obligatory linked to release of glutamate, the role of system $\mathrm{x}_{\mathrm{c}}^{-}$in nonvesicular glutamate release has been investigated in some brain regions other than hippocampus. 
In rat nucleus accumbens and striatum, glutamate release via system $\mathrm{x}_{\mathrm{c}}^{-}$is the major source of extracellular glutamate (Baker et al., 2002; Massie et al., 2011). However, this function of system $\mathrm{x}_{\mathrm{c}}^{-}$may be compartmentalized because it does not critically contribute to extracellular glutamate levels in prefrontal cortex (Melendez et al., 2005).

The present study first resolved that system $\mathrm{x}_{\mathrm{c}}^{-}$is not crucial for GSH synthesis and redox balance in the hippocampus in vivo, and that xCT knock-out $\left(x C T^{-/-}\right)$mice do not develop hippocampal atrophy and spatial memory deficits with aging, in contrast to mice lacking EAAC1 (Aoyama et al., 2006). These findings are unexpected in view of the existing in vitro literature data. Next, we provided the first evidence that system $\mathrm{x}_{\mathrm{c}}^{-}$regulates extracellular hippocampal glutamate levels and might consequently affect brain excitability. Given that system $\mathrm{x}_{\mathrm{c}}^{-}$was never studied as a target for controlling epileptic seizures, we investigated the susceptibility of $x C T^{-1-}$ mice to limbic seizures and showed for the first time that convulsion thresholds in several rodent limbic seizure models are altered by $\mathrm{xCT}$ deletion as well as by increased system $\mathrm{x}_{\mathrm{c}}^{-}$activity.

\section{Materials and Methods}

Experiments were performed according to national guidelines on animal experimentation and were approved by the Ethical Committee for Animal Experimentation of the Faculty of Medicine and Pharmacy of the Vrije Universiteit Brussel. All efforts were made to minimize animal suffering. All experiments were performed by scientists blinded to the genotype of the mice.

\section{Animals}

$x C T^{-/-}$mice used in this study were descendants of the strain described previously (Sato et al., 2005). Mice were outbred to C57BL/6 mice for at least 12 generations. Wild-type littermates were used as controls. All mice used in this study were males of 12-16 weeks (young mice, 25-35 g) or 12-18 months old (old mice, 40-50 g) and were bred in the animal facilities of the Vrije Universiteit Brussel. All rats used in this study were male albino Wistar rats weighing 270-330 g (Charles River Laboratories).

\section{Genotyping}

Genotypes were confirmed by PCR of tail DNA, using the REDExtract-NAmp Tissue PCR kit (Sigma) and the following primers: 5'-GATGCCCTTCAGCTCGATGCGGTTCACCAG-3' (GFPR3); 5' -CAGAGCAGCCCTAAGGCACTTTCC-3' [mxCT5' flankF6]; 5' -CCGATGACGCTGCCGATGATGATGG-3' [mxCT(Dr4)R8]. Genotypes were confirmed on the protein level by Western blotting for $\mathrm{xCT}$ on hippocampal samples (see Fig. 4h).

\section{Glutathione assay}

After the animals were killed, the hippocampus of each animal was quickly dissected and homogenized in an ice-cold buffer containing 2 mM EDTA and $20 \mathrm{~mm}$ Tris at pH 7.4. Homogenates were centrifuged for $15 \mathrm{~min}$ at $10,000 \times \mathrm{g}$, and the protein content of the supernatant was determined using a Quant-iT Protein Assay Kit (Invitrogen). The GSH content of the supernatant was analyzed using a QuantiChrom GSH Assay Kit according to the instructions of the manufacturer (BioAssay Systems). The method essentially comprised a deproteination step followed by a colorimetric reaction of GSH with 5,5'-dithiobis(2-nitrobenzoic acid), yielding a yellow reaction product. Optical density at 415 $\mathrm{nm}$ was measured on a plate reader.

\section{Western blotting}

Protein extraction and Western blotting were performed as described previously (Massie et al., 2008, 2010). Primary antibodies comprised guinea pig antibody to VGLUT1 (1:2000; Millipore), mouse antibody to VGLUT2 (1:5000; Millipore), rabbit antibody to VGLUT3 (1:1000; Synaptic Systems), rabbit antibody to GLT-1 $(1: 30,000)$ (Yamada et al., 1998), rabbit antibody to glutamate-aspartate transporter (GLAST; 1:4000) (Shibata et al., 1997), rabbit antibody to EAAC1 (1:1000; Alpha
Diagnostic), rabbit antibody to xCT (1:10,000) (Massie et al., 2008), mouse antibody to synaptophysine (1:5000; Stressgen), rabbit antibody to glyceraldehyde 3-phosphate dehydrogenase (GAPDH; 1:5000; Santa Cruz Biotechnology), and mouse antibody to GAPDH (1:15,000; Millipore). Antibodies were visualized by chemiluminescence (ECL Plus kit; GE Healthcare) after incubation with horseradish peroxidase conjugated antibody to rabbit, mouse, or guinea pig IgG. Optical densities of protein bands were measured using NIH ImageJ software and normalized to the density of GAPDH visualized on the same membrane.

\section{Immunohistochemistry}

Brain slicing and colorimetric staining were performed as described previously (Massie et al., 2010). Primary antibodies comprised rabbit antibody to 4-hydroxy-2-nonenal (HNE; 1:500; Alpha Diagnostic), rabbit antibody to nitrotyrosine (NT; $1: 100$; Millipore), and rabbit antibody to heme oxygenase-1 (HO-1; 1:10,000; Stressgen) and were visualized using a Vectastain ABC kit (Vector Laboratories) and the glucose oxidasediaminobenzidine-nickel method. Confocal microscopy was performed on $40 \mu \mathrm{m}$ free-floating slices. Sections were washed in PBS, and nonspecific interactions were blocked by $1 \mathrm{~h}$ incubation in 5\% normal donkey serum (NDS), $2 \%$ bovine serum albumin (BSA), and $0.3 \%$ Triton X-100 in PBS. Antibody incubations were conducted individually and sequentially. Antibodies, rabbit anti-GFAP (1:1000; Dako) and mouse antiNeuN (1:1000; Millipore), were diluted in 0.3\% Triton X-100, 0.1\% BSA, and $1 \%$ NDS in PBS and incubated with sections overnight at $4^{\circ} \mathrm{C}$. Antibodies were visualized with donkey Alexa IgG (1:800; Invitrogen) in 2\% BSA in PBS. Nuclear staining was resolved using TOPRO-3 (Invitrogen).

\section{Brain morphology measurements}

All imaging measurements were performed blinded for genotype using ImageJ software. The surface area of the dorsal hippocampus was determined on coronal cresylviolet stained $40 \mu \mathrm{m}$ sections along its rostrocaudal axis at $-1.30,-1.46,-1.70,-2.06$, and $-2.30 \mathrm{~mm}$ caudal from bregma (one measurement per anatomical level per animal, and $n=3-4$ animals per group). Cortical thinning was evaluated by measuring the thickness of cortex on cresylviolet stained $40 \mu \mathrm{m}$ slices at anatomical levels matched for all experimental groups between -2.80 and -3.80 $\mathrm{mm}$ caudal from bregma (six pooled measurements per animal, and $n=$ 13-19 animals per group). Analysis of the total width of the CA1, the pyramidal layer width of the CA1, and the cell density of GFAP+ cells in the CA1, CA3, and dentate gyrus (DG) was performed on coronal GFAPand TOPRO-3-stained sections matched for all experimental groups at approximately $-1.5,-1.7,-1.9$, and $-2.2 \mathrm{~mm}$ caudal from bregma (four pooled measurements per animal, and $n=5-6$ animals per experimental group).

\section{In vivo microdialysis in mice and rats}

Microdialysis in rat hippocampus was performed as described previously (Smolders et al., 2004). Mice were anesthetized with xylazine/ketamine $(10 / 100 \mathrm{mg} / \mathrm{kg}$, i.p.) before being mounted on a stereotactic frame. They received subcutaneously $50 \mu \mathrm{l}$ of a $0.1 \%(\mathrm{w} / \mathrm{v})$ lidocaine solution before scalp incision. A microdialysis guide (CMA/7; CMA/Microdialysis) was implanted in hippocampus $2 \mathrm{~mm}$ above final probe membrane location with the following coordinates relative to bregma: $+3.0 \mathrm{~mm}$ mediolateral, $-2.7 \mathrm{~mm}$ rostrocaudal, and $-1.5 \mathrm{~mm}$ dorsoventral. The animals received ketoprofen $(4 \mathrm{mg} / \mathrm{kg}$ i.p.) as postoperative analgesia. They were placed in microdialysis cages to recover and received food and water ad libitum. After removing the inner guide, a CMA/7 (2 mm membrane) microdialysis probe was inserted. Probes were perfused overnight with Ringer's solution containing (in $\mathrm{mM}$ ) $147 \mathrm{NaCl}, 2.3 \mathrm{CaCl}_{2}$, and $4 \mathrm{KCl}$ at $70 \mathrm{nl} / \mathrm{min}$. Dialysate sampling started $20 \mathrm{~h}$ after surgery. To exclude that changes in basal dialysate levels are the result of an impact of genetic deficiencies on in vivo recovery, we determined the real extracellular glutamate concentration via the ultraslow flow method by collecting microdialysis samples at $3.5 \mathrm{~h}$ time intervals at this flow rate of $70 \mathrm{nl} / \mathrm{min}$. Next, the flow rate was increased to $2 \mu \mathrm{l} / \mathrm{min}$. After at least an additional hour of equilibration, six baseline samples were collected at $20 \mathrm{~min}$ intervals. Glutamate content was determined in each sample as described previously (Van Hemelrijck et al., 2005). Probe positioning was histologically verified at the end of the experiments. 
Locomotor activity and spatial memory tasks

Animals were housed in groups of two to four. Mice were handled $2 \mathrm{~min}$ daily for $5 \mathrm{~d}$ before behavioral testing. Animals adapted to the testing room overnight before initiating experiments.

Open field. Spontaneous locomotor activity was monitored in a Plexiglas box (sides, $60 \mathrm{~cm}$; height, $60 \mathrm{~cm}$ ). The center zone was defined within a virtual perimeter set at $10 \mathrm{~cm}$ from the sides of the box. Distance moved, movement speed, mobility time, and time spent in the center zone were analyzed using a video tracking system and Ethovision 3.0 tracking software (Noldus).

Water maze. The water maze setup consisted of a circular pool made of black plastic (diameter, $150 \mathrm{~cm}$; height, $100 \mathrm{~cm}$ ) surrounded by a white curtain, providing distal spatial cues, in which mice were trained to locate a clear Plexiglas platform (diameter, $10 \mathrm{~cm}$ ). The pool was filled with water $\left(20-22^{\circ} \mathrm{C}\right)$ opacified with a nontoxic white paint. The training sequence consisted of $3 \mathrm{~d}$ of visible platform training (four trials per day, $60 \mathrm{~s}$ trials, $15 \mathrm{~s}$ on platform, $5 \mathrm{~min}$ intertrial interval), immediately followed by $6 \mathrm{~d}$ of hidden platform training (idem visible platform) and a probe trial $(30 \mathrm{~s})$. Between consecutive trials, the mice were placed in a cage and warmed by a $100 \mathrm{~W}$ infrared lamp. Escape latency, escape path, swimming speed, and the time spent in the virtual quadrants of the maze were analyzed using Noldus Ethovision 3.0 tracking system. The visible platform was changed to different locations in the pool between consecutive trials. One of the possible platform locations was centered in the pool to encourage a randomized search pattern. Start quadrants were varied between trial days. Starting and platform locations were randomized between mice. The hidden platform was located in the center of one of the four virtual quadrants, $30 \mathrm{~cm}$ from the edge of the pool. Platform locations were assigned to the mice in a semirandom order. Start quadrants were varied for each of the mice between consecutive trials to stimulate a spatial search strategy. The probe trial was performed $2 \mathrm{~h}$ after the hidden platform training with the platform removed from the pool. Mice were introduced in the quadrant opposite to the target quadrant and were allowed $30 \mathrm{~s}$ to search for the platform. Spatial acuity was expressed as the percentage of time spent in each of the four virtual quadrants. Target quadrant preference was used as a measure of spatial long-term memory.

Y-maze. The Y-maze apparatus consisted of three arms with walls of 35 $\mathrm{cm}$ long, $5 \mathrm{~cm}$ wide, and $8 \mathrm{~cm}$ high, allowing the mice to see distal spatial landmarks. The insides of the arms were identical, providing no intramaze cues.

Continuous spontaneous alternation testing was performed by placing the mice in the Y-maze for $8 \mathrm{~min}$ with all three arms open. The number and sequence of arms entered were recorded manually. The total number of arm entries was used as measure for locomotor activity and motivation to explore the maze. The percentage alternation (i.e., the number of alternations divided by the total possible alternations and multiplied by 100 ) was used as a measure of spatial working memory (Sarnyai et al., 2000). One alternation was counted when mice visited the three different arms consecutively. Immediate reentries were discounted. Delayed spontaneous alternation testing was performed by placing the mice into one of the arms of the maze (start arm) and allowing them to explore the maze with one of the arms closed for $15 \mathrm{~min}$ (training trial). The mice were subsequently transferred to a holding cage. After a 5 min interval, the mice were placed into the start arm and allowed to explore all three arms of the maze for $5 \mathrm{~min}$ (test trial). The number of entries into each arm, time spent in each arm, and the first choice of entry were recorded manually. Dwell time in each of the arms was analyzed using the Ethovision 3.0 video tracking system. Preference for the novel arm in the delayed version of the Y-maze was used as a measure for spatial short-term memory (Sarnyai et al., 2000).

\section{Epileptic seizure monitoring and models}

Twenty-four hour video electroencephalogram telemetry monitoring. Mice were anesthetized with xylazine/ketamine $(10 / 100 \mathrm{mg} / \mathrm{kg}$, i.p.) and received subcutaneously $50 \mu \mathrm{l}$ of a $0.1 \%(\mathrm{w} / \mathrm{v})$ lidocaine solution for local anesthesia. An incision was made in the abdomen and the scalp. A transmitter (model TA10EA-F20; Data Science International) was placed in the abdomen of each animal. After tunneling the electrical leads of the transmitter to the skull, the abdomen was sutured. Next, each animal was placed on a stereotactic frame. Holes were made in the skull. Both electrodes were shortly bent at the tip and placed directly on the dura mater (epidural lead placement) at following coordinates: $-2 /+2 \mathrm{~mm}$ lateral and -2.1 rostrocaudal. Electrodes were covered with dental acrylic cement (Dentsply Caulk) and the scalp was sutured. Mice were given ketoprofen $(4 \mathrm{mg} / \mathrm{kg}$, i.p.) and were allowed to recover for $7 \mathrm{~d}$. The obtained electroencephalogram (EEG) spectra were analyzed using Notocordhem Evolution software (Notocord).

Chemoconvulsant models. Kainic acid, an agonist at ionotropic kainate glutamate receptors, or pilocarpine, an agonist of muscarinic cholinergic receptors, both affect initially and predominantly hippocampal brain regions after their systemic administration. Therefore, they are valuable models of partial (focal) seizures with complex symptomatology and secondary generalization from the limbic focus and useful models to simulate complex partial seizures in humans (Velisek, 2006). Moreover, a kainic acid analog produced temporal lobe epilepsy in humans after ingestion of infested mussels, and the seizure-inducing potential of cholinergic activity-enhancing nerve gasses has been documented in men as well (Velisek, 2006)

The threshold for different phases of pilocarpine- or kainic acidinduced seizure activity was determined by intravenous infusion of pilocarpine $(24 \mathrm{mg} / \mathrm{ml})$ or kainic acid $(7.5 \mathrm{mg} / \mathrm{ml})$ in the lateral tail vein at a constant rate of $150 \mu \mathrm{l} / \mathrm{min}$ (Kaminski et al., 2005). Methylscopolamine ( $1 \mathrm{mg} / \mathrm{kg}$, s.c.) was injected $30 \mathrm{~min}$ before pilocarpine infusion to prevent peripheral cholinergic symptoms. During the experiment, the animal could freely move in a Plexiglas cage. The following end points were used to determine the seizure threshold. For pilocarpine the end points were (1) head nodding, (2) bilateral myoclonus, (3) clonic seizures with loss of righting reflexes, (4) tonic hindlimb extension, and (5) death. For kainic acid they were (1) behavioral arrest, (2) falling, (3) clonic convulsions for at least $5 \mathrm{~s},(4)$ tonic hindlimb extension, and (5) death. Time was measured from the start of the infusion until the onset of these stages. Seizure thresholds were determined for each animal according to the following equation: dose (milligrams per kilogram $)=($ duration of infusion $(\mathrm{sec}-$ onds) $\times$ rate of infusion (milliliters per minute) $\times$ drug concentration (milligrams per milliliter $) \times 1000) /(60 \mathrm{~s} \times$ weight of mouse $($ grams $))$.

NMDA is the prototype agonist at the ionotropic NMDA glutamate receptors, which are prominently expressed in hippocampal CA1 and gyrus dentatus regions. Some suggested that NMDA-induced seizures might mimic refractory seizures, but clearly these NMDA-evoked seizures in mature rodents simulate best the tonic-clonic seizure patterns also observed in humans (Velisek, 2006).

NMDA was injected intraperitoneally at doses of 100 and $125 \mathrm{mg} / \mathrm{kg}$ (concentrations were tested separately in different animals). Convulsions were scored as described in von Lubitz et al. (1993). The initial convulsion time is the time that the first convulsion with a score of 3 appears.

Mean body weights of mice used for the chemoconvulsant model experiments were $32.71 \pm 1.03 \mathrm{~g}$ for $x \mathrm{CT}^{+/+}$mice and $33.13 \pm 0.71 \mathrm{~g}$ for $x C T^{-/-}$mice.

Six hertz model. The $6 \mathrm{~Hz}$ model of partial seizures is a low frequency stimulation paradigm resulting in a seizure characterized by jaw and forelimb clonus, immobility, and an elevated Straub tail. It is the only acute electrically induced seizure model in which levetiracetam has displayed anticonvulsant activity, suggesting that this model may be useful for discovery of compounds with unique anticonvulsant mechanisms and to simulate therapy-resistant epilepsy (White et al., 2006).

The protocol for the $6 \mathrm{~Hz}$ seizure model was as described previously (Kaminski et al., 2004). Topical anesthetic (0.5\% tetracaine) was applied to the cornea before corneal stimulation $(0.2 \mathrm{~ms}$ duration pulses at $6 \mathrm{~Hz}$ for 3 s), administered by a constant-current device (ECT Unit 57800; Ugo Basil). Each animal was tested only once at a selected current intensity in the range of 9-53 $\mathrm{mA}$. The current intensity values were chosen using the staircase procedure in which the stimulation intensity for an animal was based on whether the preceding animal did or did not exhibit a seizure. The seizure was characterized by stun, forelimb clonus, twitching of the vibrissae, and Straub tail for at least $45 \mathrm{~s}$. Mice not experiencing seizures exhibited normal exploratory behavior. In each experiment, groups of four or five Naval Medical Research Institute mice were tested at five or six stimulation intensities. The convulsant current required to 

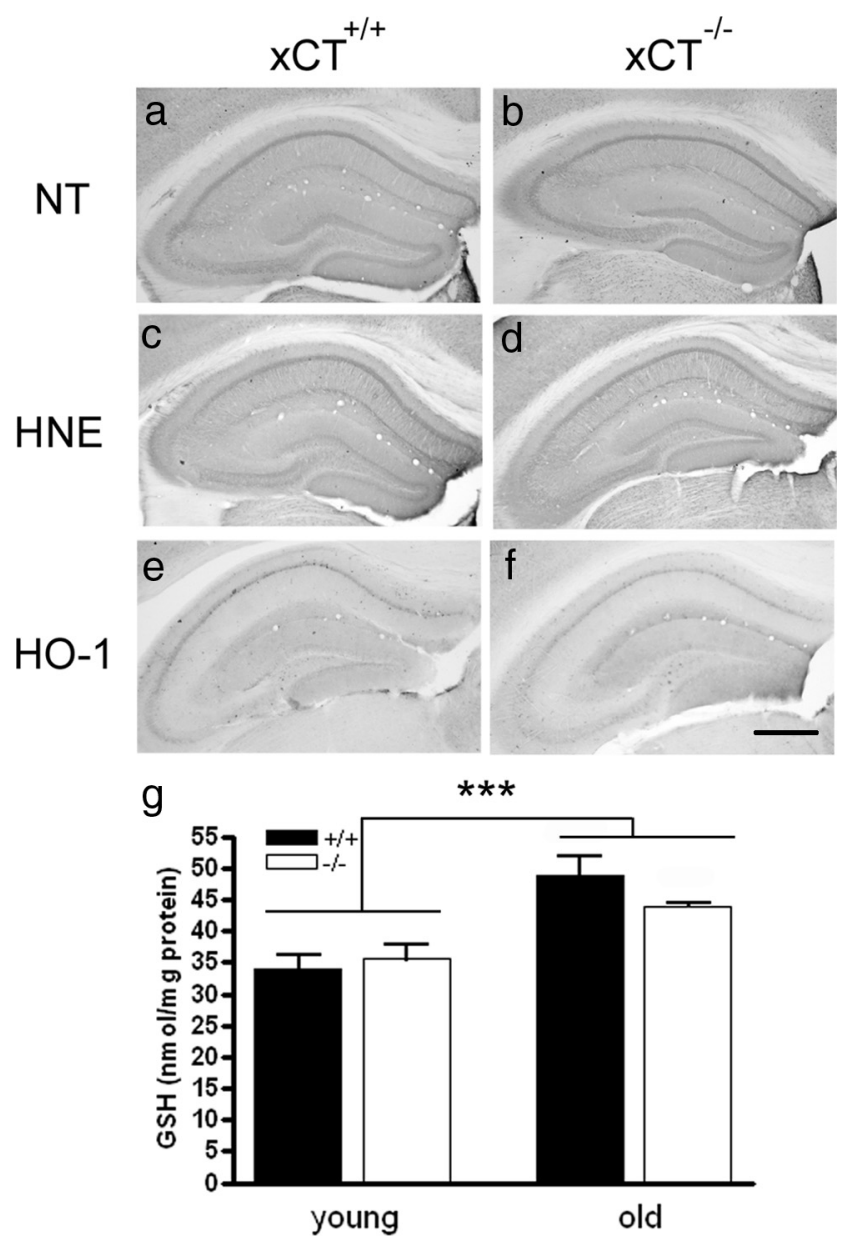

Figure 1. Oxidative-stress-related markers and glutathione levels in $x \mathrm{CT}^{-/-}$mice. $\boldsymbol{a}-\boldsymbol{f}$, Representative photomicrograph of immunohistochemical detection of oxidative-stress-related proteins in hippocampus of old (12-18 months) $x \mathrm{CT}^{+/+}$and $x \mathrm{CT}^{-/-}$mice $(n=6$ for each genotype). No difference was seen in labeling pattern forNT $(\boldsymbol{a}, \boldsymbol{b}), \mathrm{HNE}(\boldsymbol{c}, \boldsymbol{d})$ or HO-1 (e, $\boldsymbol{f}) . \boldsymbol{g}$, Hippocampal GSH content in young and old $x C^{+/+}$and $x C T^{-/-}$mice $(n=6$ for each genotype and age). Scale bar, $500 \mu \mathrm{m}$. Statistics as denoted in Results: ${ }^{* *} p<0.001$.

produce a seizure in $50 \%\left(\mathrm{CC}_{50}\right)$ of the population was calculated by probit analysis.

\section{Statistics}

Data are expressed as means \pm SEM. Statistical analysis was performed using GraphPad Prism 4.0 software. For studying one variable within one group of animals, we used Student's paired $t$ test. For investigating the effect of genotype on one variable, we used the Mann-Whitney test. The effect of genotype on more than one variable was assessed by two-way ANOVA followed by Bonferroni's post hoc test. The appropriate statistical test is denoted for each experiment in the Results section. The $\alpha$ value was set at 0.05 for each statistical test.

\section{Results}

All experiments were performed by scientists blinded to the genotype of the mice.

\section{Hippocampal glutathione content and oxidative-stress-related markers in $x C T^{-/-}$mice}

$\mathrm{xCT}$ deletion in young (12-16 weeks) or old (12-18 months) mice did not affect the hippocampal expression pattern of several oxidative-stress-related markers, such as NT (Fig. $1 a, b)$, HNE $(c, d)$, and HO-1 $(e, f)$. For hippocampal GSH content, we observed an age-dependent increase (two-way ANOVA; $F_{(1,20)}=24.52 ; p<$
0.0001 ) but no effect of genotype [two-way ANOVA; $F_{(1,20)}=1.82$; not significant (n.s.)] (Fig. $1 g$ ). These observations suggest that $x C T^{-\ell-}$ mice can compensate for the loss of cystine import through system $\mathrm{x}_{\mathrm{c}}^{-}$and subsequent shortage of cysteine for GSH synthesis.

\section{Lack of brain atrophy and glial cell loss in the hippocampus of} $x C T^{-/-}$mice

Figure $2 a$ illustrates the overall hippocampal anatomy in young and old $x C T^{+/+}$and $x C T^{-/-}$mice. No genotype differences were observed for the surface area of the dorsal hippocampus over its total rostrocaudal axis (Fig. $2 b, c$ ) in either young mice (two-way ANOVA; $F_{(1,6)}=0.76$; n.s.) or old mice (two-way ANOVA; $F_{(1,5)}=$ 0.74 ; n.s.). We did not observe an effect of genotype (two-way ANOVA; $F_{(1,58)}=2.49$; n.s.) but observed an overall effect of age (two-way ANOVA; $F_{(1,58)}=41.02 ; p<0.0001$ ) on cortex width (Fig. $2 d$ ). No genotype differences (two-way ANOVA; $F_{(1,19)}=$ 0.39 ; n.s.) or age differences (two-way ANOVA; $F_{(1,19)}=0.05$; n.s.) were observed in young or old mice for the width of the CA1 region (Fig. 2e). Similarly, no genotype differences (two-way ANOVA; $F_{(1,19)}=0.78 ;$ n.s.) or age differences (two-way ANOVA; $F_{(1,19)}=0.40$; n.s.) were observed in young or old mice for the width of the pyramidal cell layer in the CA1 (Fig. $2 f$ ). This indicates the absence of extensive neurodegeneration. Moreover, no genotype effects were observed for the number of GFAPpositive cells per area in the CA1, CA3, and DG of the hippocampus (two-way ANOVA; $F_{(1,54)}=0.85 ;$ n.s.) in young and old $x C T^{-/-}$ and $x \mathrm{CT}^{+/+}$mice (Fig. $2 g$ ). However, an increase in the number of GFAP-positive cells per area was observed in the CA1 (two-way ANOVA; $F_{(1,18)}=5.53 ; p=0.03$ ), CA3 (two-way ANOVA; $F_{(1,18)}=$ $11.5 ; p=0.003$ ), and DG (two-way ANOVA; $F_{(1,18)}=17.8 ; p=$ 0.0006 ) in old compared with young mice (Fig. $2 g-i$ ).

\section{Normal open-field behavior of $x C T^{-/-}$mice}

Figure $3 a$ illustrates the absence of genotype differences between young or old $x C T^{-/-}$and $x C T^{+/+}$mice for the distance traveled (two-way ANOVA; $F_{(1,41)}=0.23$; n.s.), the average movement speed (two-way ANOVA; $F_{(1,41)}=0.56$; n.s.) and the percentage of time spent in the center of the open field (two-way ANOVA; $F_{(1,41)}=0.50$; n.s.). This indicates that $x C T^{-/-}$mice do not have gross motor dysfunction, motivational deficits for exploring a novel environment, or increased aversion for the center of an open field. An overall effect of age was observed for the travel distance (two-way ANOVA; $F_{(1,41)}=72.2 ; p<0.0001$ ) and movement speed (two-way ANOVA; $F_{(1,41)}=95.7 ; p<0.0001$ ) but not for time spent in the center of the open field (two-way ANOVA; $F_{(1,41)}=0.61 ;$ n.s. $)$.

\section{Intact spatial reference memory in $x C T^{-/-}$mice}

Escape latency analysis (two-way ANOVA) for visible platform testing in young (Fig. $3 b$ ) and old (e) mice revealed no significant main effect of genotype (young, $F_{(1,30)}=0.04$, n.s.; old, $F_{(1,25)}=$ 0.85 , n.s.), no significant genotype-by-day interaction (young, $F_{(2,30)}=0.96$, n.s.; old, $F_{(2,50)}=0.86$, n.s.), but a highly significant effect of trial day in both young $\left(F_{(2,30)}=194.79 ; p<0.0001\right)$ and old $\left(F_{(2,50)}=61.7 ; p<0.0001\right)$ mice, indicating that mice with $\mathrm{xCT}$ deletion were equally as efficient as their $x \mathrm{CT}^{+/+}$controls at learning the nonspatial aspects of the water maze task. Swimming speed genotype effects (young, $F_{(1,30)}=0.49$, n.s.; old, $F_{(1,30)}=$ 0.04 , n.s.) and genotype-by-day effects (young, $F_{(2,30)}=0.11$, n.s.; old, $F_{(1,30)}=0.04$, n.s.) were not significant during visible platform testing in young (Fig. $3 b$ ) and old (e) mice.

In the hidden platform setup, escape latency analysis (two-way ANOVA) revealed no effect of genotype (young, $F_{(1,15)}=3.33$, n.s.; 
a

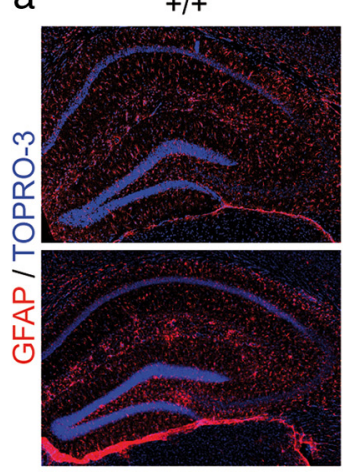

$-/-$

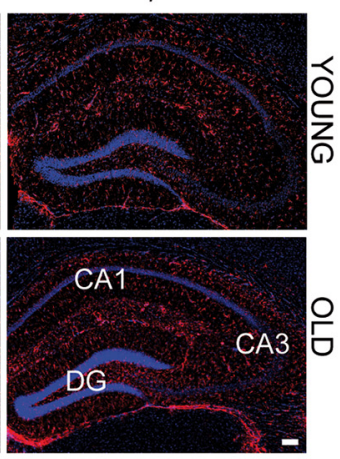

b

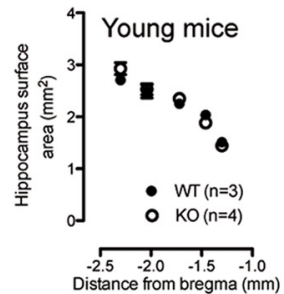

C

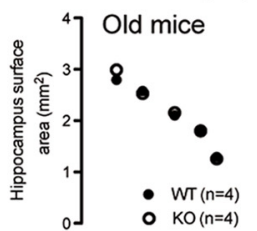

e

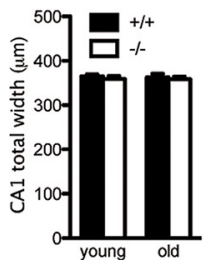

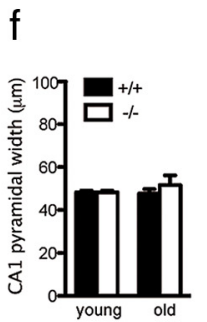

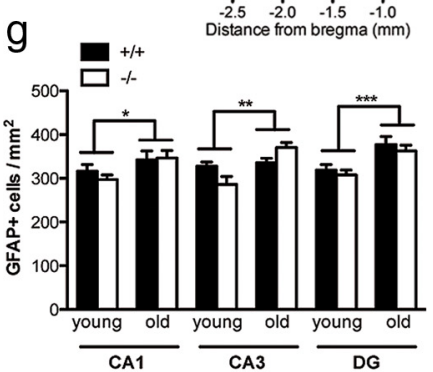

$\mathrm{h}$ Young mice
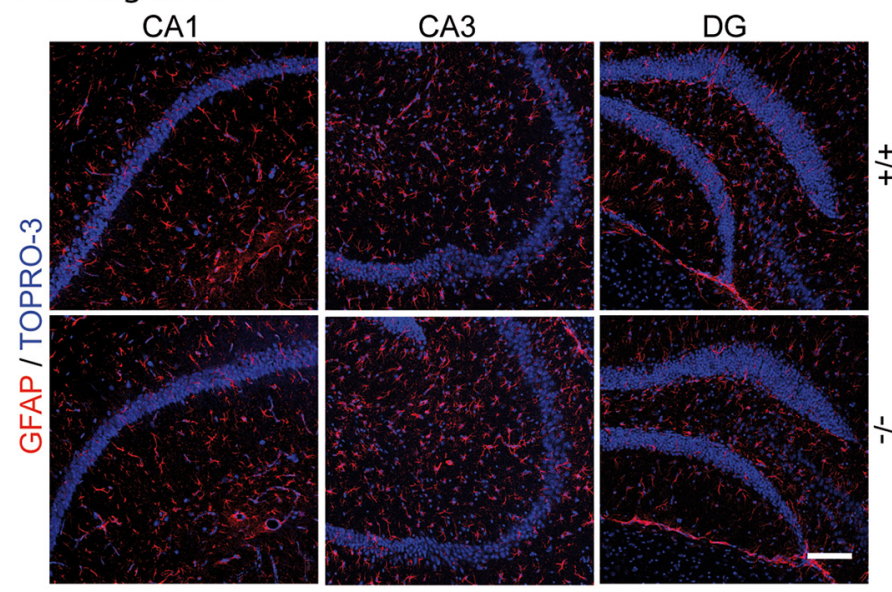

i Old mice
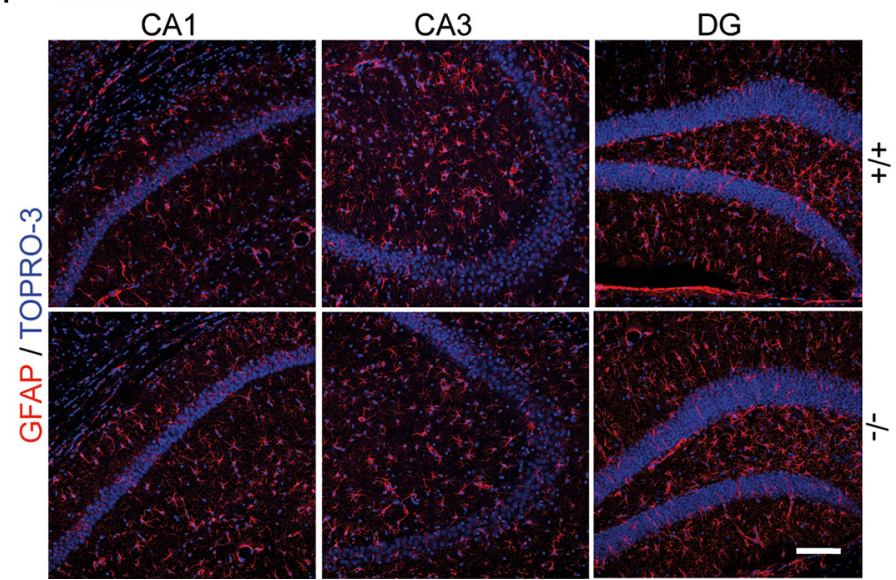

Figure 2. Lack of brain atrophy and loss of glial cells in the hippocampus of $x \mathrm{CT}^{-/-}$mice. $\boldsymbol{a}$, Representative immunohistochemical stainings for GFAP (red) together with nuclear stain TOPRO-3 (blue) in the dorsal hippocampus of young (12-16 weeks; top) and old (12-18 months; bottom) $x C T^{+/+}$and $x \mathrm{CT}^{-/-}$mice. $\boldsymbol{b}, \boldsymbol{c}$, Surface area of the dorsal hippocampus in matched corona sections of young $(\boldsymbol{b})$ and old $(\boldsymbol{c}) x\left(T^{+/+}\right.$and $x \mathrm{CT}^{-/-}$mice $(n=3-4$ animals per group). $\boldsymbol{d}$, Cortical thinning as evaluated by comparing the width of the cortex in matched coronal sections of young and old $x \mathrm{CT}^{+/+}$and $x \mathrm{CT}^{-/-}$mice $(n=13-19$ animals per group). $\boldsymbol{e}, \boldsymbol{f}$, Total width of the $\mathrm{CA} 1(\boldsymbol{e})$ and width of the pyramidal layer of the $\mathrm{CA} 1(\boldsymbol{f})$ in young and old $x \mathrm{CT}^{+/+}$and $x \mathrm{CT}^{-/-}$ old, $F_{(1,25)}=0.11$, n.s.), no genotype-by-day interaction (young, $F_{(5,75)}=1.06$, n.s.; old, $F_{(5,125)}=0.90$, n.s. $)$, but a highly significant effect of trial day (young, $F_{(5,75)}=4.32, p<$ 0.002 ; old, $\left.F_{(5,125)}=12.87, p<0.0001\right)$, demonstrating that both young and old $x C T^{-/-}$and $x C T^{+/+}$mice were capable of learning the spatial memory task in the water maze setup (Fig. 3b,e). Nevertheless, young $x C T^{-/-}$mice showed a tendency of learning the hidden platform water maze task less efficiently. Swimming speed genotype effects (young, $F_{(5,75)}=0.06$, n.s.; old, $F_{(5,125)}=0.01$, n.s. $)$ and genotype-by-day interactions (young, $F_{(5,75)}=0.09$, n.s.; old, $F_{(5,125)}=0.82$, n.s.) were not significant during hidden platform testing in young (Fig. $3 b$ ) or old (e) mice.

When comparing the average escape latencies of the first and last trial within a day for the first three days of hidden platform testing (Fig. 3c,f, left) we observed no genotype effect (young, $F_{(1,15)}=1.74$, n.s.; old, $F_{(1,25)}=0.22$, n.s.) or genotypeby-trial interaction (young, $F_{(1,15)}=0.72$, n.s.; old, $F_{(1,25)}=2.07$, n.s.). The overall effect of trial number was significant in young mice $\left(F_{(1,15)}=6.45 ; p=0.022\right)$ and borderline significant in old mice $\left(F_{(1,15)}=\right.$ 4.04; $p=0.055)$. This indicates that task performance improves comparably within a day for both genotypes. When comparing the average escape latencies of the last trial of a day and the first trial of the following day for the first three days of hidden platform testing (Fig. $3 c, f$, right) we observed no genotype effect (young, $F_{(1,15)}=2.87$, n.s.; old, $F_{(1,25)}=0.07$, n.s.), genotype-bytrial interaction (young, $F_{(1,15)}=0.00$, n.s.; old, $F_{(1,25)}=0.15$, n.s.), or trial effect (young, $F_{(1,15)}=0.37$, n.s.; old, $F_{(1,25)}=$ 0.19 , n.s.). This indicates that task performance does not deteriorate significantly between consecutive trial days and suggests intact reference memory in young and old mice of either genotype.

Retention of spatial search strategies was evaluated in young (Fig. $3 d$ ) and old $(g)$ mice in a probe trial performed $2 \mathrm{~h}$ after the final hidden platform training session. Two-way ANOVA revealed no

\section{$\longleftarrow$}

mice determined on matched coronal sections of the dorsal hippocampus ( $n=5-6$ animals per group). $\boldsymbol{g}$, Quantification of the number of GFAP-positive cells in matched sections of the $C A 1, C A 3$ and $D G$ of the dorsal hippocampus in young and old $x C T^{+/+}$and $x C T^{-/-}$mice ( $n=5-6$ animals per group). $\boldsymbol{h}, \boldsymbol{i}$, Representative immunohistochemical stainings for GFAP (red) and nuclear stain TOPRO-3 (blue) as used for the quantification of GFAP-positive cells. Statistics are as denoted in the results section: ${ }^{*} p<0.05$; ${ }^{* *} p<0.01$; ${ }^{* * *} p<0.001$. Scale bars: $100 \mu \mathrm{m}$. 


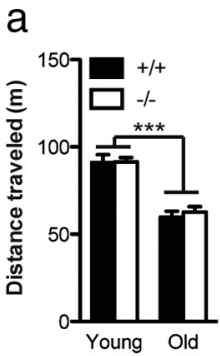

b Young mice

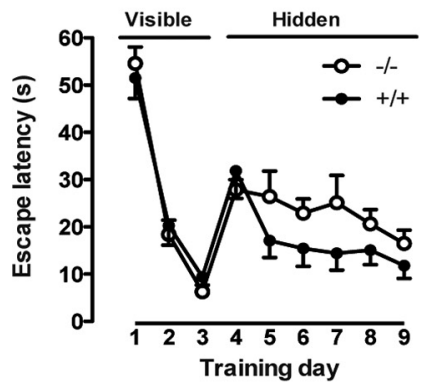

e Old mice

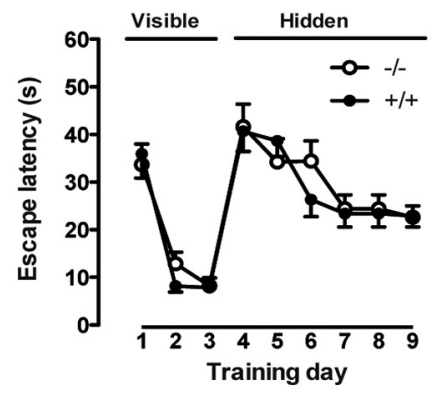

h Young mice
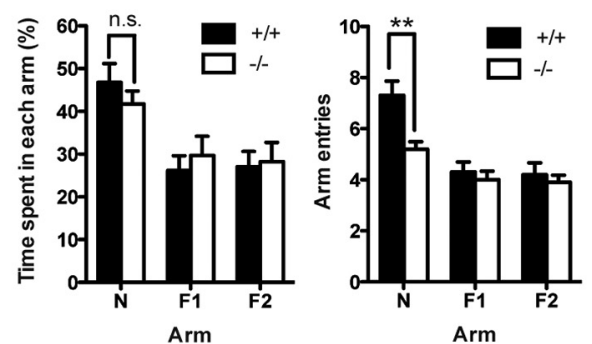
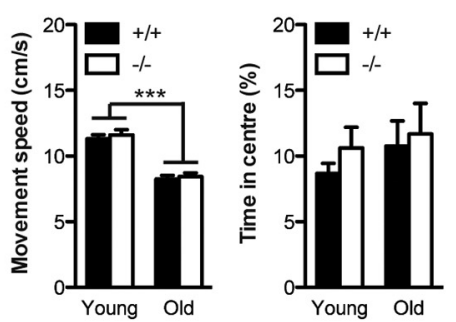

\section{Young mice}
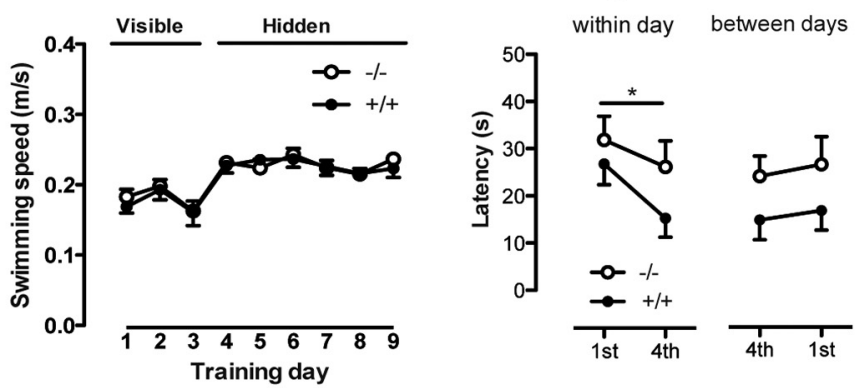

$f$ Old mice
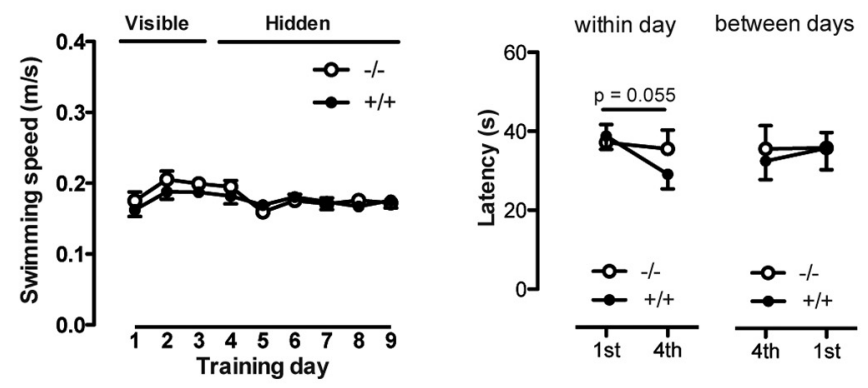

i Old mice
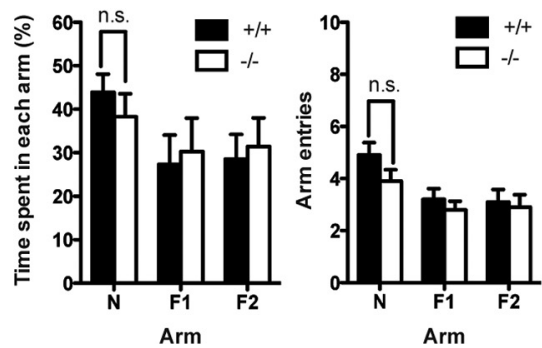

$\mathrm{g}$ Old mice

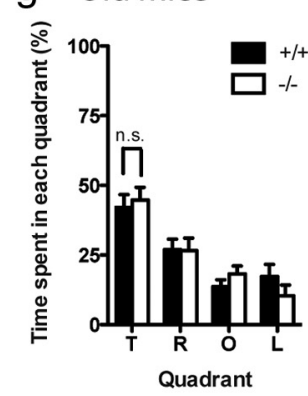

d Young mice

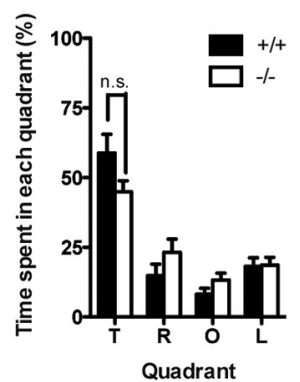

Figure 3. Behavioral characterization of young and old $x \mathrm{CT}^{+/+}$and $x \mathrm{CT}^{-/-}$mice. $\boldsymbol{a}, 0$ pen-field locomotor activity, i.e., distance moved, movement speed, and time spent in the center (young mice, $n=8-9$ for each genotype; old mice, $n=13-14$ for each genotype). $\boldsymbol{b}, \boldsymbol{e}$, Escape latency and swimming speed of young $(\boldsymbol{b})(n=8-9$ for each genotype) and old (e) ( $n=13-14$ for each genotype) $x\left(T^{+/+}\right.$and $x\left(T^{-/-}\right.$mice in the water maze task. $c, f$, Average change in escape latency on the first and last trial within a day for the first three days of hidden platform testing (left) and average change in escape latency on the last trial of a day and the first trial of the next day between the first three days of hidden platform testing (right) in young mice $(c)(n=8-9$ per genotype) and old mice $(\boldsymbol{f})(n=13-14$ per genotype). $\boldsymbol{d}, \boldsymbol{g}$, Preference for the quadrants left (L), right (R) or opposite (0) to the target (T) during the probe trial performed $2 \mathrm{~h}$ after completion of water maze training. $\boldsymbol{h}, \boldsymbol{i}$, Preference for the novel (N) and familiar (F1, F2) arms during a delayed $\mathrm{Y}$-maze spontaneous alternation task ( $n=10$ for each genotype and age). $\boldsymbol{j}$, The alternation score and number of arm entries in a Y-maze spontaneous alternation task $\left(n=10\right.$ for each genotype and age). Statistics are as denoted in the results section: ${ }^{*} p<0.05 ;{ }^{* *} p<0.01 ;{ }^{* * *} p<0.001$.

genotype effects (young, $F_{(1,15)}=0.20$, n.s.; old, $F_{(1,25)}=0.35$, n.s.) or genotype-by-target quadrant interactions (young, $F_{(1,15)}=$ 0.20 , n.s.; old, $F_{(1,25)}=0.35$, n.s.), but both young and old $x C T^{-/-}$ and $x C T^{+/+}$mice showed a clear preference for the target quadrant (young, $F_{(3,45)}=31.90, p<0.0001,44.9 \pm 4.0 \%$ for $x \mathrm{CT}^{-/-}$, $58.8 \pm 6.6 \%$ for $x C T^{+/+}$; old, $F_{(3,75)}=17.76, p<0.0001$, $44.7 \pm 4.5 \%$ for $x C T^{-/-^{-}}, 42.1 \pm 4.6 \%$ for $x C T^{+/+}$). This further demonstrates that spatial reference memory is intact in young and old $x \mathrm{CT}^{-/-}$and $x C T^{+/+}$mice.
Impaired spatial working memory in $\mathrm{xCT}^{-/-}$mice

In the delayed Y-maze spontaneous alternation task, we observed a significant target arm effect, with both young (two-way ANOVA; $F_{(2,36)}=30.75 ; p<0.0001$ ) and old mice (two-way ANOVA; $\left.F_{(2,36)}=17.13 ; p<0.0001\right)$ making more entries in the novel arm of the Y-maze after a previous exposure to two familiar arms (Fig. $3 h, i$, right). A significant genotype-by-target arm interaction was observed in young mice (two-way ANOVA; $F_{(2,36)}=5.38 ; p=$ 0.009 ), with $x \mathrm{CT}^{-/-}$mice making less entries into the novel arm 
compared to $x \mathrm{CT}^{+/+}$mice (Bonferroni's post hoc test; $p<0.01$; number of novel arm entries, $5.2 \pm 0.3$ for $x C T^{-/-}$mice, $7.3 \pm$ 0.6 for $x C T^{+/+}$mice), but not in old mice (two-way ANOVA; $F_{(2,36)}=1.14 ;$ n.s. $)$. Further analysis of the number of arm entries with two-way ANOVA showed no main effect of genotype in either young mice (Fig. $3 h)\left(F_{(1,18)}=4.36\right.$; n.s.) or old mice (Fig. 3i) $\left(F_{(1,18)}=0.99\right.$; n.s. $)$. When analyzing dwell times in each of the Y-maze arms, no significant main effect of genotype (young, two-way ANOVA, $F_{(1,18)}=2.74$, n.s.; old, $F_{(1,18)}=1.00$, n.s.) or genotype-by-target arm interaction (young, two-way ANOVA, $F_{(2,36)}=0.42$; n.s.; old, $F_{(2,36)}=0.22$, n.s.) was observed in either young or old mice (Fig. $3 h, i$, left). Young $x \mathrm{CT}^{-/-}$and $x \mathrm{CT}^{+/+}$ littermates spent significantly more time in the novel arm of the Y-maze (two-way ANOVA; $F_{(2,36)}=7.77 ; p=0.002$ ). However, the dwell-time preference of old $x C T^{-/-}$and $x C T^{+/+}$mice for the novel arm of the Y-maze was not significant (two-way ANOVA; $F_{(2,36)}=1.63 ;$ n.s.).

In the continuous $Y$-maze spontaneous alternation task (Fig. $3 j$ ), an overall genotype effect (two-way ANOVA; $F_{(1,36)}=10.33$; $p=0.0028$ ) was observed for the alternation score (Fig. $3 j$, left), with young $x \mathrm{CT}^{-/-}$making less correct alternations compared to young $x \mathrm{CT}^{+/+}$mice (Bonferroni's post hoc test, $p<0.05$ ). We observed no significant age effect (two-way ANOVA; $F_{(1,36)}=0.25$; n.s.) or genotype-by-age interaction (two-way ANOVA; $F_{(1,36)}=$ 2.58 ; n.s.). No genotype effect (two-way ANOVA; $F_{(1,36)}=0.19$; n.s.), genotype-by-age interaction (two-way ANOVA; $F_{(1,36)}=$ 1.46; n.s.), or age effect (two-way ANOVA; $F_{(1,36)}=3.37$; n.s.) was observed for the number of arm entries made by young or old $x C T^{+/+}$and $x C T^{-/-}$mice (Fig. $3 j$, right). This indicates that the decrease in alternation score in young $x \mathrm{CT}^{-1-}$ mice was attributable to a spatial working memory deficit rather than a deficit in locomotor activity or exploratory motivation.

\section{System $\mathrm{x}_{\mathrm{c}}^{-}$is an important source of extracellular glutamate in the mouse hippocampus}

We observed a significant effect of genotype on glutamate dialysate concentrations (two-way ANOVA; $F_{(1,18)}=16.13 ; p=$ 0.0008 ), with significantly lower glutamate concentrations in baseline dialysis samples obtained from young $\left(x C T^{+/+}, 0.208 \pm\right.$ $0.036 \mu \mathrm{M} ; x C T^{-/-}, 0.079 \pm 0.022 \mu \mathrm{M}$; Bonferroni's post hoc test, $p<0.05)$ as well as old $\left(x C T^{+/+}, 0.191 \pm 0.034 \mu \mathrm{M} ; x C T^{-/-}\right.$, $0.084 \pm 0.015 \mu \mathrm{M}$; Bonferroni's post hoc test, $p<0.05) x C T^{-/-}$ mice compared to their age-matched $x C T^{+/+}$littermates (Fig. $4 a$ ). We measured in the same dialysates the levels of aspartate, which is not a substrate for system $\mathrm{x}_{\mathrm{c}}^{-}$(Patel et al., 2004), as a negative control. No difference in extracellular aspartate levels could be observed between $x C T^{+/+}$mice and $x \mathrm{CT}^{-/-}$mice, independent of age $\left(x C T^{+/+}\right.$young, $0.028 \pm 0.006 \mu \mathrm{M} ; x C T^{-/-}$ young, $0.020 \pm 0.006 \mu \mathrm{M} ; x C T^{+/+}$old, $0.031 \pm 0.006 \mu \mathrm{M}$; $x C T^{-/-}$old, $0.027 \pm 0.003 \mu \mathrm{M}$; two-ANOVA, $F_{(1,22)}=1.31$, n.s.) (Fig. $4 b$ ). Using the ultraslow flow method, we also measured significantly lower real extracellular glutamate concentrations in the $x C T^{-/-}$mice $(0.690 \pm 0.163 \mu \mathrm{M} ; n=6)$ compared with their wild-type controls (2.337 $\pm 0.491 \mu \mathrm{M} ; n=7$; Mann-Whitney $U=4.00, p=0.014)$, meaning that in $x C T^{-/-}$as well as $x C T^{+/+}$ mice the in vivo recovery is $\sim 10 \%$.

\section{Inhibitors of system $x_{c}^{-}$decrease extracellular glutamate in rat hippocampus}

In Figure $4 c$, rat hippocampal glutamate dialysate levels following pharmacological manipulation are expressed as the percentage of their corresponding hippocampal glutamate baseline levels. Lowering $\mathrm{Ca}^{2+}$ in the perfusion fluid from 2.3 to $1.0 \mathrm{~mm}$ did not alter extracellular glutamate levels (Student's $t$ test; $t_{(4)}=0.75 ;$ n.s.). Reversal of the day-night cycle and performing microdialysis during the dark phase, when rodents are more active, has been shown previously to effectively enhance neuronally released cortical acetylcholine levels (Sarter and Bruno, 1994). Nevertheless, perfusion of the microdialysis probe, inserted in the hippocampus of rats habituated to a reversed day-night rhythm, with a Ringer's solution without $\mathrm{Ca}^{2+}$ ions (Student's $t$ test; $t_{(3)}=0.26$; n.s.) or containing the voltage-dependent $\mathrm{Na}^{+}$-channel blocker tetrodotoxin (TTX; $1 \mu \mathrm{M}$; Student's $t$ test, $t_{(3)}=1.64$, n.s.) during the dark phase did not affect hippocampal dialysate glutamate levels. These pharmacological manipulations, commonly used to verify vesicular release, produced a pronounced attenuation of hippocampal dopamine dialysate levels in the same experimental conditions (data not shown). This demonstrates that maintenance of basal hippocampal glutamate levels is predominantly $\mathrm{Ca}^{2+}$ and $\mathrm{Na}^{+}$independent. However, reverse microdialysis of nonselective inhibitors of system $x_{c}^{-}$(Melendez et al., 2005), (RS)-2-chloro-5-hydroxyphenylglycine (CHPG; $100 \mu \mathrm{M}$; Student's $t$ test, $\left.t_{(4)}=3.15, p=0.034\right)$ or LY367385 $((+)$-2-methyl4-carboxyphenylglycine; $1 \mathrm{~mm}$; Student's $t$ test, $t_{(6)}=7.33, p<$ 0.001 ), significantly decreased hippocampal glutamate levels. This CHPG- or LY367385-induced attenuation of extracellular glutamate is more likely to originate from inhibition of system $\mathrm{x}_{\mathrm{c}}^{-}$ rather than their GGluR $_{1 / 5}$ antagonist properties, given that reverse microdialysis of the $\mathrm{mGluR}_{1 / 5}$ antagonist AIDA ((RS)-1aminoindan-1.5-dicarboxylic acid; $600 \mu \mathrm{M})$ failed to alter hippocampal glutamate concentrations (Student's $t$ test, $t_{(3)}=$ 1.10, n.s.).

\section{Stimulation of glutamate/cystine exchange via system $\mathrm{x}_{\mathbf{c}}^{-}$enhances glutamate levels in rat hippocampus}

Reverse dialysis of $\mathrm{N}$-acetylcysteine (N-Ac; $1 \mathrm{mM}$ ), a precursor of cysteine known to activate system $\mathrm{x}_{\mathrm{c}}^{-}$, significantly enhanced the extracellular hippocampal glutamate levels as measured with microdialysis in conscious rats (basal glutamate levels, $0.370 \pm$ $0.121 \mu \mathrm{M} ; \mathrm{N}-\mathrm{Ac}, 0.726 \pm 0.194 \mu \mathrm{M}$; Student's $t$ test, $t_{(5)}=3.79$, $p=0.013)$ (Fig. 4c).

\section{No changes in hippocampal glutamate transporter expression in $x C T^{-1-}$ mice}

We studied possible compensatory changes in hippocampal protein expression of the major glial glutamate transporters GLT-1 and GLAST, the neuronal EAAC1 transporter that can also function as a cysteine transporter, and the vesicular glutamate transporters (VGLUT1-VGLUT3) in response to xCT gene deletion. Hippocampal expression levels of either the vesicular glutamate transporters or synaptophysine, a synaptic vesicle protein whose abundance provides a synaptic marker, were not different between $x \mathrm{CT}^{-/-}$and $x C T^{+/+}$mice (Fig. $4 d, f$ ) (two-way ANOVA; VGLUT1, $F_{(1,14)}=0.18$, n.s.; VGLUT2, $F_{(1,16)}=0.00$, n.s.; VGLUT3, $F_{(1,14)}=0.10$, n.s.; synaptophysine, $F_{(1,14)}=0.00$, n.s.). Hippocampal expression of VGLUT1 (two-way ANOVA; $F_{(1,14)}=$ $5.11 ; p=0.04$ ) and VGLUT3 (two-way ANOVA; $F_{(1,14)}=33.02$; $p<0.0001$ ) as well as synaptophysine (two-way ANOVA; $F_{(1,14)}=7.75$; $p=0.01)$ showed an age-dependent decrease, contrary to VGLUT2 (two-way ANOVA; $F_{(1,16)}=0.93$; n.s.). Also, the expression levels of the glial high-affinity $\mathrm{Na}^{+} / \mathrm{K}^{+}$-dependent glutamate transporters (GLT-1, two-way ANOVA, $F_{(1,14)}=0.08$, n.s.; GLAST, two-way ANOVA, $F_{(1,15)}=0.03$, n.s.) and the neuronal EAAC1 transporter (two-way ANOVA; $F_{(1,15)}=0.10$; n.s.) were not different between $x \mathrm{CT}^{-/-}$mice and $x C T^{+/+}$littermates. Though expression levels of GLAST (two-way ANOVA; 
a

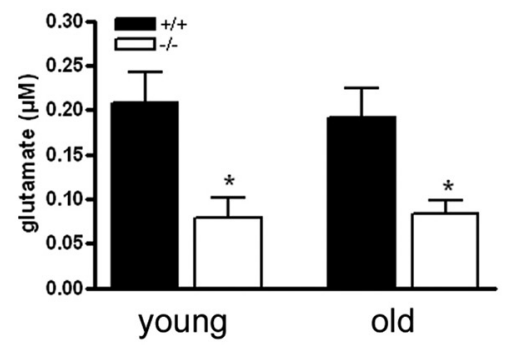

C

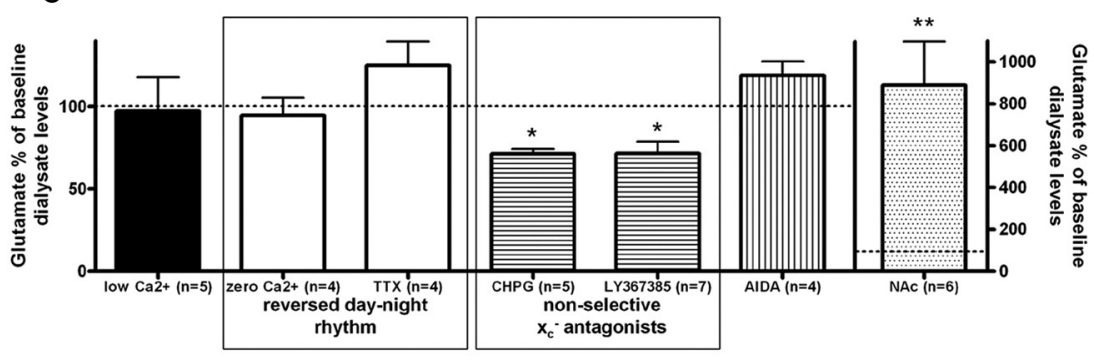

d

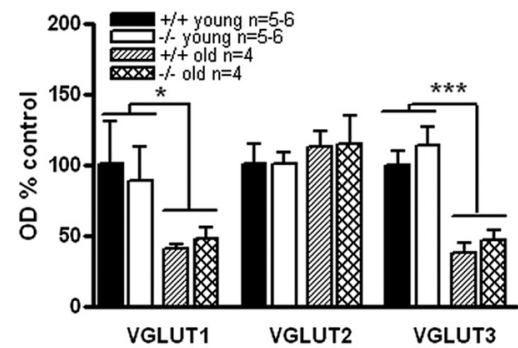

f

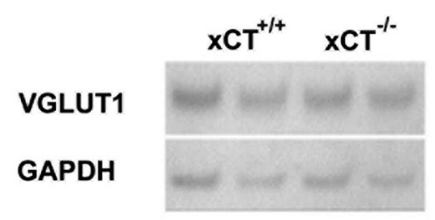

VGLUT2

GAPDH

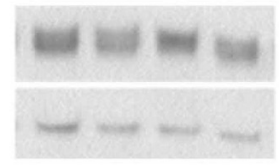

VGLUT3

GAPDH

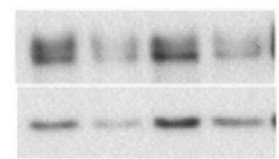

Synap

GAPDH

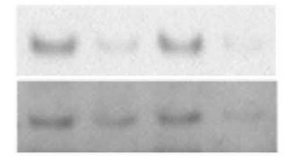

b

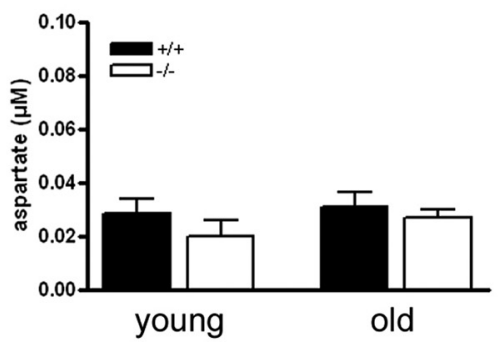

e

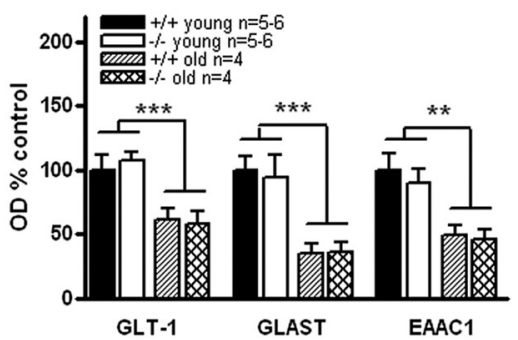

g

GLT-1

GAPDH

GLAST

GAPDH

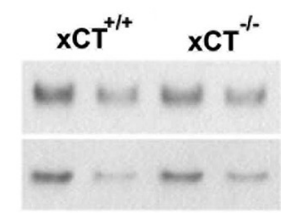

EAAC1

GAPDH

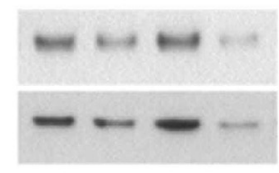

h

XCT

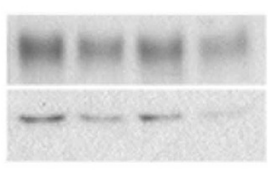

$+/+-/-\quad+/+-/-$

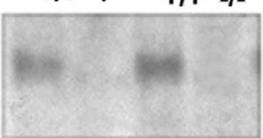

Figure 4. Glutamate transporter expression and extracellular glutamate levels in hippocampus of $x \mathrm{C}^{-/-}$mice. $\boldsymbol{a}, \boldsymbol{b}$, Extracellular glutamate ( $\boldsymbol{a}$ ) and aspartate $(\boldsymbol{b})$ concentrations in hippocampus of young ( $n=4-5$ for each genotype) and old ( $n=7-8$ for each genotype) $x \mathrm{CT}^{-/-}$and $x \mathrm{CT}^{+/+}$mice as measured using in vivo microdialysis. c, Relative glutamatelevels (expressed in \% relative to basal levels) in rat hippocampus ( $n=4-7)$ after pharmacological manipulation of exocytosis (low $\left.\mathrm{Ca}^{2+}, \mathrm{TTX}\right)$, system $\mathrm{x}_{\mathrm{c}}^{-}$(CHPG, LY367385, and N-Ac), or mGluR ${ }_{1 / 5}(\mathrm{AIDA}$ ) as well as after reversing day-night rhythm. $\boldsymbol{d}-\boldsymbol{g}$, Hippocampal protein expression levels of VGLUT1-3 (d), and GLAST, GLT-1, and EAAC1 (e) ( $n=4-6$ for each genotype) inyoung and old $x C^{+/+}$and $x C^{-/-}$mice.f, $\boldsymbol{g}$, A representative example of a Western blotting experiment (2 concentrations of each sample were loaded). Upper bands correspond to VGLUT1 ( 50 kDa), VGLUT2 ( $\sim 55 \mathrm{kDa})$, VGLUT3 $(\sim 60 \mathrm{kDa})$, synaptophysine $(\sim 38 \mathrm{kDa})$, GLAST $(\sim 55 \mathrm{kDa})$, GLT-1 $(\sim 55 \mathrm{kDa})$, or EAAC1 $(\sim 60 \mathrm{kDa})$, and lower bands to GAPDH ( $\sim 35 \mathrm{kDa}) . \boldsymbol{h}$, xCT immunoreactivity was absent in hippocampal samples of $x\left(T^{-/-}\right.$mice, whereas in $x \mathrm{CT}^{+/+}$mice we observed a band with a molecular weight of $\sim 35 \mathrm{kDa}$. Statistics are as denoted in the results section: ${ }^{*} p<0.05 ;{ }^{* *} p<0.01$; ${ }^{* * *} p<0.001$.

$\left.F_{(1,15)}=18.53 ; p=0.0006\right)$, GLT-1 (twoway ANOVA; $\left.F_{(1,14)}=24.05 ; p=0.0002\right)$, as well as EAAC1 (two-way ANOVA; $\left.F_{(1,15)}=16.29 ; p=0.0011\right)$ were decreased in aged mice, independent of genotype (Fig. 4e,g). In conclusion, these findings demonstrate that, although as a result of aging all transporters related to glutamate reuptake as well as two vesicular glutamate transporters are downregulated in hippocampus, protein expression levels of all glutamate transporters are unaffected by genotype, and no compensatory up regulations or downregulations are observed as a result of the loss of xCT protein (Fig. 4h).

No spontaneous epileptic seizures were detected in $x C T^{-/-}$mice

Basal electroencephalographic activity obtained from the cortex of four $x C T^{+/+}$ and five $x C T^{-/-}$mice was monitored at least $5 \mathrm{~h}$ a day during an entire month. Every 2 d, the basal EEG of the mice was measured overnight for at least $12 \mathrm{~h}$. These EEG recordings did not show any appearance of cortical abnormalities in the $x C T^{-/-}$mice and were comparable to the baseline EEG spectra of $x C T^{+/+}$ littermates (Fig. 5a). Focal seizure activity within specific brain sites cannot be excluded by these recordings from the cortical surface.

$x C T^{-/-}$mice are less susceptible to

limbic seizures with secondary

generalization

Infusion of pilocarpine or kainic acid into the lateral tail vein of mice produced an array of rapidly progressing behaviors. Both chemoconvulsants induced limbic seizures with secondary generalization in mice, though with a different behavioral convulsion pattern. Intravenous pilocarpine infusion induced head bobbing and bilateral forelimb clonus with rearing, followed by clonic convulsions with loss of righting reflexes (falling), tonic hindlimb extension, and death in all mice. Yet, a significantly higher dose of pilocarpine was necessary to induce these behaviors in $x C T^{-1-}$ mice compared with $x \mathrm{CT}^{+/+}$littermates (Fig. $5 b$ ). We revealed a significant effect of genotype on the threshold dose of pilocarpine for inducing bilateral myoclonus $\left(x C T^{+/+}\right.$, $414.2 \pm 11.8 \mathrm{mg} / \mathrm{kg} ; x C T^{-/-}, 469.4 \pm 18.4$ $\mathrm{mg} / \mathrm{kg}$; Mann-Whitney $U=11.00 ; p=$ $0.028)$, clonic convulsions with loss of righting reflexes $\left(x C T^{+/+}, 455.0 \pm 14.8 \mathrm{mg} / \mathrm{kg}\right.$; $x C T^{-/-}, 526.0 \pm 22.4 \mathrm{mg} / \mathrm{kg}$; Mann-Whitney $U=9.00 ; p=0.015)$, tonic hindlimb extension $\left(x C T^{+/+}, 464.2 \pm 13.5 \mathrm{mg} / \mathrm{kg}\right.$; $x C T^{-/-}, 544.2 \pm 21.5 \mathrm{mg} / \mathrm{kg}$; Mann-Whit- 
ney $U=8.00 ; p=0.010)$, and death $\left(x C T^{+/+}, 486.3 \pm 14.1 \mathrm{mg} / \mathrm{kg} ; x C T^{-/-}\right.$, $570.2 \pm 22.7 \mathrm{mg} / \mathrm{kg}$; Mann-Whitney $U=$ 9.00; $p=0.015)$.

Kainic acid infusion induced behavioral arrest, followed by falling, clonic convulsions, tonic hindlimb extension, and death in all mice. The dose of kainic acid, necessary to induce the consecutive typical behaviors, was however significantly higher in the $x C T^{-/-}$mice compared with their $x C T^{+/+}$littermates (Fig. $5 c$ ). This effect reached significance for behavioral arrest $\left(x C T^{+/+}, 33.4 \pm 1.6 \mathrm{mg} /\right.$ $\mathrm{kg} ; x C T^{-/-}, 60.7 \pm 2.9 \mathrm{mg} / \mathrm{kg}$; MannWhitney $U=0.00 ; p=0.004)$, falling $\left(x C T^{+/+}, 54.3 \pm 2.7 \mathrm{mg} / \mathrm{kg} ; x C T^{-/-}\right.$, $71.2 \pm 2.6 \mathrm{mg} / \mathrm{kg}$; Mann-Whitney $U=$ 2.00; $p=0.017)$, the clonic phase $\left(x C T^{+/+}, 58.1 \pm 2.5 \mathrm{mg} / \mathrm{kg} ; x C T^{-/-}\right.$, $75.6 \pm 3.3 \mathrm{mg} / \mathrm{kg}$; Mann-Whitney $U=$ $2.00 ; p=0.017)$, the tonic phase $\left(x C T^{+/+}\right.$, $65.4 \pm 3.6 \mathrm{mg} / \mathrm{kg} ; x C T^{-/-}, 82.5 \pm 3.4 \mathrm{mg} /$ kg; Mann-Whitney $U=2.00 ; p=0.017)$, and death $\left(x C T^{+/+}, 68.0 \pm 3.8 \mathrm{mg} / \mathrm{kg}\right.$; $x C T^{-/-}, 86.0 \pm 3.4 \mathrm{mg} / \mathrm{kg}$; Mann-Whitney $U=2.00 ; p=0.017$ ).

Intraperitoneal injection of a third chemoconvulsant, NMDA, at doses of 100 and $125 \mathrm{mg} / \mathrm{kg}$, resulted in a mortality rate of respectively 13 and $71 \%$ in $x C T^{+/+}$ mice, respectively, whereas in $x C T^{-/-}$ mice the mortalities were, respectively, 0 and $20 \%$ (Fig. $5 d$, right). Moreover, the initial convulsion time, which is the time until the first convulsion with a score of 3 , as described in von Lubitz et al. (1993), was significantly higher in $x C T^{-/-}$mice $(100 \mathrm{mg} / \mathrm{kg}, 152.9 \pm 37.0 \mathrm{~s} ; 125 \mathrm{mg} / \mathrm{kg}$, $220.0 \pm 58.1 \mathrm{~s})$ compared to $x C T^{+/+}$mice $(100 \mathrm{mg} / \mathrm{kg}, 99.6 \pm 12.5 \mathrm{~s}$, Mann-Whitney $U=25.0$, n.s.; $125 \mathrm{mg} / \mathrm{kg}, 82.0 \pm$ $32.8 \mathrm{~s}$, Mann-Whitney $U=4.0, p=0.03$ ) (Fig. $5 d$, middle). Also, the average convulsion score was significantly smaller in $x C T^{-/-}$mice $(100 \mathrm{mg} / \mathrm{kg}, 1.8 \pm 0.3 ; 125$ $\mathrm{mg} / \mathrm{kg}, 2.4 \pm 0.8)$ compared to their wildtype littermates $(100 \mathrm{mg} / \mathrm{kg}, 2.6 \pm 0.5$, Mann-Whitney $U=5.5, p=0.003 ; 125$ $\mathrm{mg} / \mathrm{kg}, 4.3 \pm 0.6$, Mann-Whitney $U=$ 5.5, $p=0.048$ ) (Fig. 5d, left).

\section{Stimulation of glutamate/cystine exchange via system $\mathrm{x}_{\mathrm{c}}^{-}$ is proconvulsive}

C57BL/6 mice treated with N-Ac (90 mg/kg, i.p.), a cyst(e)ine prodrug, 90 min before the start of pilocarpine infusion via the tail vein were significantly more susceptible to pilocarpine-induced head bobbing (saline, $302.7 \pm 21.4 \mathrm{mg} / \mathrm{kg} ; \mathrm{N}-\mathrm{Ac}, 237.3 \pm 9.8 \mathrm{mg} / \mathrm{kg}$; Mann-Whitney $U=3.00 ; p=0.015$ ), rearing (saline, $543.3 \pm 26.6$ $\mathrm{mg} / \mathrm{kg}$; N-Ac, $436.2 \pm 18.7 \mathrm{mg} / \mathrm{kg}$; Mann-Whitney $U=3.00 ; p=$ 0.015 ), clonic convulsions with loss of righting reflexes (saline, $586.8 \pm 24.5 \mathrm{mg} / \mathrm{kg} ; \mathrm{N}-\mathrm{Ac}, 526.2 \pm 11.6 \mathrm{mg} / \mathrm{kg} ;$ Mann-Whitney $U=4.00 ; p=0.026$ ), tonic hindlimb extension (saline, $606.8 \pm 26.0$

a b

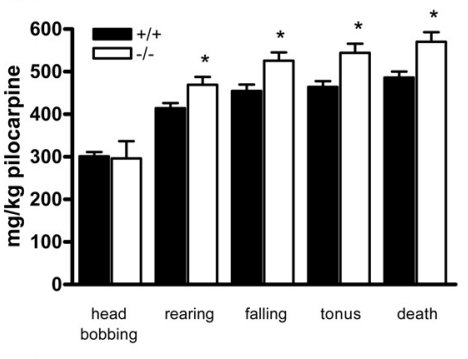

d
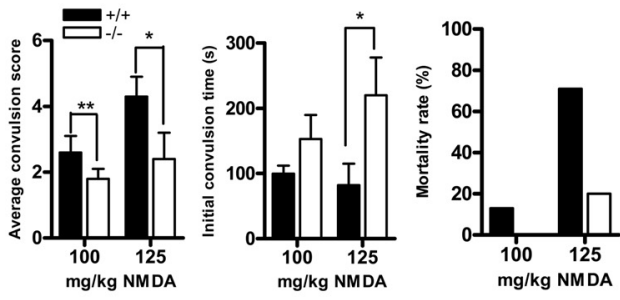

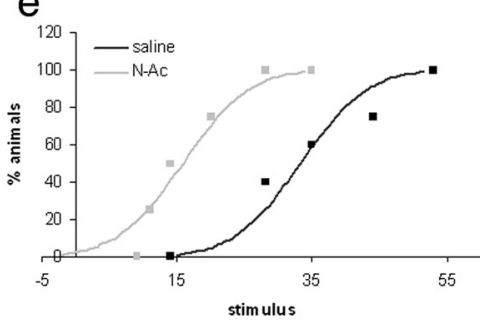

g

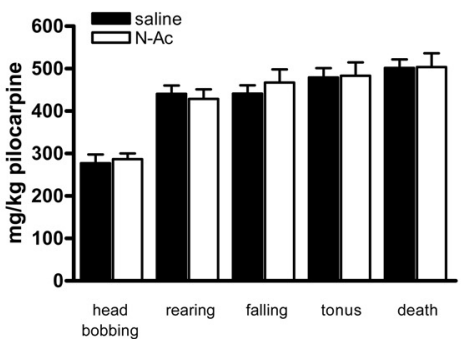

C

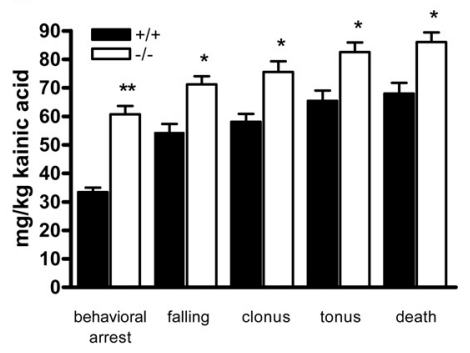

e

bobbin
Figure 5. Seizure susceptibility of $x \mathrm{CT}^{-/-}$mice. $\boldsymbol{a}$, A representative excerpt of a basal EEG in $x \mathrm{CT}^{+/+}$and $x C \mathrm{~T}^{-/-}$mice. $\boldsymbol{b}, \boldsymbol{c}$, Graphical representation of the threshold doses of pilocarpine ( $n=8$ for each genotype) (b) and kainic acid ( $n=6$ for each genotype) (c) needed to induce the typical consecutive behaviors in $x \mathrm{CT}^{+/+}$and $x \mathrm{CT}^{-/-}$mice in the acute tail vein infusion model. $\boldsymbol{d}$, Average convulsion score, initial convulsion time, and mortality rate after $100 \mathrm{mg} / \mathrm{kg}$ ( $n=8$ for each genotype) and $125 \mathrm{mg} / \mathrm{kg}$ ( $n=5-7$ for each genotype) Data points indicate the percentage of animals exhibiting seizures when tested at the stimulation current value shown on the abscissa $(n=$ $4-5$ for each data point). $\boldsymbol{f}, \boldsymbol{g}$, Threshold doses of pilocarpine needed to induce the consecutive behaviors after saline and N-Ac injection in C57BL/6 mice $(n=6)(f)$ and $x\left(T^{-1-}\right.$ mice $(n=5)(g)$. Statistics are as denoted in the results section: ${ }^{*} p<0.05 ;{ }^{* *} p<0.01$.

$\mathrm{mg} / \mathrm{kg} ; \mathrm{N}-\mathrm{Ac}, 541.8 \pm 10.9 \mathrm{mg} / \mathrm{kg}$; Mann-Whitney $U=3.00 ; p=$ 0.015 ), and death (saline, $620.5 \pm 27.0 \mathrm{mg} / \mathrm{kg} ; \mathrm{N}-\mathrm{Ac}, 558.8 \pm 12.0$ $\mathrm{mg} / \mathrm{kg}$; Mann-Whitney $U=4.00 ; p=0.026$ ) (Fig. $5 f$ ). The proconvulsant effect of $\mathrm{N}$-Ac $(90 \mathrm{mg} / \mathrm{kg}$, i.p.) was completely abolished in the $x \mathrm{CT}^{-/-}$animals (Fig. $5 g$ ). No difference was observed in susceptibility for pilocarpine thresholds between $\mathrm{N}$-Ac-treated and salineinjected $x C T^{-/-}$animals.

The proconvulsant effect of N-Ac was also demonstrated in the $6 \mathrm{~Hz}$ electrical corneal stimulation seizure model (Fig. 5e). In mice treated with $\mathrm{N}-\mathrm{Ac}(90 \mathrm{mg} / \mathrm{kg}$, i.p.), $6 \mathrm{~Hz}$ stimulation currents of $11 \mathrm{~mA}$ induced seizures in $25 \%$ of the mice. Increasing current intensity stepwise to a level of $28 \mathrm{~mA}$ induced seizures in all N-Ac-treated mice. Higher stimulation intensities were re- 
quired to induce seizures in the saline-treated mice. A stimulation intensity of $53 \mathrm{~mA}$ was necessary to induce seizures in all saline-treated animals. A stimulation current of $28 \mathrm{~mA}$ induced seizures in two of five control mice, whereas $14 \mathrm{~mA}$ did not induce seizures in any of the saline-treated mice. The $\mathrm{CC}_{50}$ values derived from these data presented in Figure $5 e$ are $15.81 \mathrm{~mA}$ for N-Ac-treated mice (95\% confidence limit (CL); 10.02-21.85 $\mathrm{mA}$ ) and $33.23 \mathrm{~mA}$ for saline-treated mice (95\% CL; 26.31$39.362 \mathrm{~mA}$ ) (probit analysis, $p<0.001$ ).

\section{Discussion}

Disturbances in functioning of hippocampal system $\mathrm{x}_{\mathrm{c}}^{-}$can have dual physiological implications. Indeed, this antiporter provides cells with cystine that is intracellularly reduced to cysteine, the rate-limiting building block of the major brain antioxidant GSH. However, system $\mathrm{x}_{\mathrm{c}}^{-}$simultaneously transports glutamate into the extracellular space, possibly enhancing excitability and eventually leading to excitotoxicity.

In view of in vitro evidence for the role of system $\mathrm{x}_{\mathrm{c}}^{-}$in maintaining intracellular GSH levels (Albrecht et al., 2010), we studied to which extent dysfunction of system $\mathrm{x}_{\mathrm{c}}^{-}$affects hippocampal $\mathrm{GSH}$ in vivo. Homozygous $\mathrm{xCT}$ deletion had no effect on hippocampal GSH content. With aging, $x C T^{-/-}$mice did not display exacerbated cortical thinning, hippocampal atrophy, or loss of glial cells in the hippocampus. Hippocampal GSH depletion causes severe deficits in the hippocampus-dependent water maze task (Cruz-Aguado et al., 2001; Aoyama et al., 2006), whereas $x C T^{-1-}$ mice learned both the procedural and spatial aspects of the water maze task and displayed intact spatial reference memory. Together, our data strongly suggest that system $x_{c}^{-}$is not critical for hippocampal GSH synthesis and redox balance in vivo.

In this context, it should be noted that cultured astrocytes preferably obtain cysteine via import and subsequent reduction of cystine, but they are also capable of importing cysteine via system $\mathrm{x}_{\mathrm{AG}}{ }^{-}$or the high-affinity glutamate transporters (Kranich et al., 1998; Shanker and Aschner, 2001). Accordingly, GSH content and viability of mature astrocytes was primarily unaffected by blocking $\mathrm{x}_{\mathrm{c}}^{-}$transport (Shih et al., 2003; Chung et al., 2005). Therefore, brain atrophy in sut/sut mice (putative deficiency in system $\mathrm{x}_{\mathrm{c}}^{-}$) (Chintala et al., 2005; Shih et al., 2006) may not directly relate to $\mathrm{x}_{\mathrm{c}}^{-}$function. Moreover, GSH synthesis in cultured neurons mainly depends on cysteine uptake (Dringen et al., 1999). Indeed, mice lacking the neuronal glutamate transporter EAAC1 developed brain atrophy and severe spatial reference memory deficits with aging (Aoyama et al., 2006), in contrast to $x C T^{-/-}$mice, suggesting that nonneuronal $\mathrm{x}_{\mathrm{c}}^{-}$-mediated cystine uptake and subsequent GSH release is not required for EAAC1mediated cysteine uptake in neurons in vivo.

Interestingly, young $x C T^{-/-}$mice displayed a deficit in the continuous Y-maze spontaneous alternation task, indicating spatial working memory failure (Deacon and Rawlins, 2006). Intact spatial reference memory was reported previously to coexist with a deficit in spatial working memory in mice lacking the GluR1 AMPA receptor subunit (Reisel et al., 2002; Schmitt et al., 2003). Indeed, different aspects of neuronal processing within the hippocampus underlie different forms of spatial memory. Since $x C T^{-/-}$mice do not exhibit any signs of oxidative stress or brain atrophy, this cannot be the cause for the observed working memory deficit in $x C T^{-/-}$mice. Therefore, we next studied in depth the second function attributed to system $\mathrm{x}_{\mathrm{c}}^{-}$, namely, its potential role in extrasynaptic glutamate release.

Glutamate is released into the extracellular space by neurons and glia from a variety of sources, such as $\mathrm{Ca}^{2+}$-dependent exo- cytosis, $\mathrm{Ca}^{2+}$-dependent nonvesicular release, and $\mathrm{Ca}^{2+}$ - and $\mathrm{Na}^{+}$-independent release via system $\mathrm{x}_{\mathrm{c}}^{-}$. Extracellular glutamate, sampled by in vivo microdialysis, is insensitive to depletion of $\mathrm{Ca}^{2+}$ or inhibition of $\mathrm{Na}^{+}$channels with tetrodotoxin, showing that extracellular glutamate does not merely originate from synaptic exocytotic release (Del Arco et al., 2003). This implies a mainly nonvesicular origin of extracellular glutamate in the rodent hippocampus. In rodent nucleus accumbens (Baker et al., 2002) and striatum (Massie et al., 2011), but not prefrontal cortex (Melendez et al., 2005), nonvesicular glutamate release via system $\mathrm{x}_{\mathrm{c}}^{-}$is an important source of extracellular glutamate. Here we show that in rat hippocampus, extracellular glutamate is sensitive to inhibition of system $x_{c}^{-}$with CHPG and LY367385. Whereas these molecules are simultaneously capable of antagonizing metabotropic $\mathrm{mGlu}_{1 / 5}$ receptors, we sustain that these effects are mediated by $\mathrm{x}_{\mathrm{c}}^{-}$inhibition since selective $\mathrm{mGlu}_{1 / 5}$ receptor blockade with AIDA had no effect. Moreover, activation of system $\mathrm{x}_{\mathrm{c}}^{-}$ by $\mathrm{N}$-Ac significantly enhanced hippocampal glutamate dialysate levels. Finally, hippocampal extracellular glutamate was significantly lower in $x C T^{-/-}$mice compared to wild-type littermates, whereas aspartate, which is not a substrate for system $\mathrm{x}_{\mathrm{c}}^{-}$(Patel et al., 2004), was unaffected by genetic xCT deletion. These results indicate that system $\mathrm{x}_{\mathrm{c}}^{-}$is an important source of extracellular glutamate in rodent hippocampus.

Given this important contribution of system $\mathrm{x}_{\mathrm{c}}^{-}$to regulate extracellular glutamate levels in hippocampus and the known role of hippocampal glutamate in spatial working memory, the observed working memory deficit in young $x C T^{-1-}$ mice is most probably related to a dysregulation of hippocampal glutamate. With aging, the trend in working memory decline was less pronounced in $x C T^{-/-}$mice compared to $x C T^{+/+}$littermates, so that genotype differences were no longer apparent in old animals. It is tempting to speculate that this effect is attributable to the lower excitotoxic potential of glutamate in these $x C T^{-/-}$mice. Indeed, $x \mathrm{CT}^{-/-}$mice have significantly lower extracellular glutamate levels in their hippocampi and might therefore be less prone to age-dependent glutamate-mediated excitotoxic damage. This is in line with our recent findings that $x C T^{-/-}$ mice are also less susceptible to the excitotoxic effects of 6-hydroxydopamine injection (Massie et al., 2011).

From the perspective that $\mathrm{xCT}$ deletion yields a relatively mild behavioral phenotype with deficits mainly limited to working memory, we further propose that system $\mathrm{x}_{\mathrm{c}}^{-}$may be a relevant target in pathologies associated with excessive hippocampal glutamate-mediated actions, such as epilepsy. Conversely, stimulation of system $\mathrm{x}_{\mathrm{c}}^{-}$would lead to excessive extracellular hippocampal glutamate and seizures. It is well established that hippocampal glutamate-mediated excitatory effects play a crucial role in initiation and spread of epileptic seizures. In addition to the well-established neuronal mechanisms of seizure induction, a role of $\mathrm{Ca}^{2+}$-dependent astrocytic glutamate release was proposed previously (Tian et al., 2005). Here we show that $\mathrm{Ca}^{2+}$ independent astrocytic glutamate release via system $\mathrm{x}_{\mathrm{c}}^{-}$can largely affect seizure susceptibility as well. These experimental findings in rodents are in line with the hypothesis that glutamate release via system $\mathrm{x}_{\mathrm{c}}^{-}$contributes to peritumoral seizures associated with malignant gliomas in men (Sontheimer, 2003).

We indeed demonstrated that lower hippocampal extracellular glutamate in $x \mathrm{CT}^{-/-}$mice is accompanied by decreased vulnerability for chemoconvulsants that initiate limbic seizures, such as pilocarpine, kainic acid, and NMDA. These findings cast new light on a previous study in which the antiepileptic drug levetiracetam was proposed to exert neuroprotective effects by 
enhancing the endogenous antioxidant ability in rat hippocampus through increasing $\mathrm{xCT}$ expression and by decreasing the baseline glutamate dialysate levels (Ueda et al., 2009). Our present findings rather point to a proconvulsant effect of increased activity of system $x_{c}^{-}$, suggesting that the net effects of levetiracetam on the glutamate levels would rather mediate its beneficial effects. Similarly, decreased expression of both xCT and EAAC1 was described in hippocampus of old EL mice, a model for multifactorial idiopathic epilepsy (Takaki et al., 2008). Depletion of endogenous antioxidants caused by decreased xCT expression was suggested to trigger ictogenesis. However, $x \mathrm{CT}^{-/-}$mice do not show GSH depletion in hippocampus. Our data therefore suggest that ictogenesis in EL mice is not related to decreased expression of $\mathrm{xCT}$, but rather to decreased expression of EAAC1. Decreases in expression of EAAC1 have indeed been linked to diminished GABA synthesis (Sepkuty et al., 2002) and could therefore affect ictogenesis.

It is worthwhile mentioning that LY367385, a combined system $\mathrm{x}_{\mathrm{c}}^{-}$inhibitor and metabotropic $\mathrm{mGlu}_{1 / 5}$ receptor antagonist (Melendez et al., 2005), displayed anticonvulsant effects in the mouse $6 \mathrm{~Hz}$ model (Barton et al., 2003) and the pilocarpine rat model (Smolders et al., 2004). However, antagonists of metabotropic $\mathrm{mGlu}_{1 / 5}$ receptor are also potent anticonvulsive agents. Until now, adequate tools were lacking to investigate whether selective system $\mathrm{x}_{\mathrm{c}}^{-}$inhibition has any effect on seizure susceptibility.

Moreover, in the present study we showed that increased activity of system $\mathrm{x}_{\mathrm{c}}^{-}$has proconvulsant effects. Mice pretreated with $\mathrm{N}$-Ac were more susceptible to limbic seizures in both the pilocarpine model and $6 \mathrm{~Hz}$ corneal stimulation model. These proconvulsant effects are supported by clinical case reports of status epilepticus induced by intravenous N-Ac administration (Hershkovitz et al., 1996; Bailey et al., 2004). Here, we provide conclusive evidence for the role of system $\mathrm{x}_{\mathrm{c}}^{-}$in these proconvulsive effects of $\mathrm{N}$-Ac given that its effect on pilocarpine-induced seizure susceptibility was abolished in $x \mathrm{CT}^{-/-}$mice.

In conclusion, our current finding that genetic deletion of system $\mathrm{x}_{\mathrm{c}}^{-}$is anticonvulsive in a range of limbic seizure models but does not induce pervasive behavioral effects indicates that system $\mathrm{x}_{\mathrm{c}}^{-}$is an innovative target for the future development of antiepileptic drugs. We therefore emphasize the urgent need to develop selective inhibitors of system $\mathrm{x}_{\mathrm{c}}^{-}$.

\section{References}

Albrecht P, Lewerenz J, Dittmer S, Noack R, Maher P, Methner A (2010) Mechanisms of oxidative glutamate toxicity: the glutamate/cystine antiporter system $\mathrm{x}(\mathrm{c})$ - as a neuroprotective drug target. CNS Neurol Disord Drug Targets 9:373-382.

Aoyama K, Suh SW, Hamby AM, Liu J, Chan WY, Chen Y, Swanson RA (2006) Neuronal glutathione deficiency and age-dependent neurodegeneration in the EAAC1 deficient mouse. Nat Neurosci 9:119-126.

Back SA, Gan X, Li Y, Rosenberg PA, Volpe JJ (1998) Maturationdependent vulnerability of oligodendrocytes to oxidative stress-induced death caused by glutathione depletion. J Neurosci 18:6241-6253.

Bailey B, Blais R, Letarte A (2004) Status epilepticus after a massive intravenous $\mathrm{N}$-acetylcysteine overdose leading to intracranial hypertension and death. Ann Emerg Med 44:401-406.

Baker DA, Xi ZX, Shen H, Swanson CJ, Kalivas PW (2002) The origin and neuronal function of in vivo nonsynaptic glutamate. J Neurosci 22:9134-9141.

Bannai S (1986) Exchange of cystine and glutamate across plasma membrane of human fibroblasts. J Biol Chem 261:2256-2263.

Barton ME, Peters SC, Shannon HE (2003) Comparison of the effect of glutamate receptor modulators in the $6 \mathrm{~Hz}$ and maximal electroshock seizure models. Epilepsy Res 56:17-26.

Chen Y, Swanson RA (2003) The glutamate transporters EAAT2 and
EAAT3 mediate cysteine uptake in cortical neuron cultures. J Neurochem 84:1332-1339.

Chintala S, Li W, Lamoreux ML, Ito S, Wakamatsu K, Sviderskaya EV, Bennett DC, Park YM, Gahl WA, Huizing M, Spritz RA, Ben S, Novak EK, Tan J, Swank RT (2005) Slc7all gene controls production of pheomelanin pigment and proliferation of cultured cells. Proc Natl Acad Sci U S A 102:10964-10979.

Chung WJ, Lyons SA, Nelson GM, Hamza H, Gladson CL, Gillespie GY, Sontheimer H (2005) Inhibition of cystine uptake disrupts the growth of primary brain tumors. J Neurosci 25:7101-7110.

Cruz-Aguado R, Almaguer-Melian W, Díaz CM, Lorigados L, Bergado J (2001) Behavioral and biochemical effects of glutathione depletion in the rat brain. Brain Res Bull 55:327-333.

Deacon RM, Rawlins JN (2006) T-maze alternation in the rodent. Nat Protoc $1: 7-12$.

Del Arco A, Segovia G, Fuxe K, Mora F (2003) Changes in dialysate concentrations of glutamate and GABA in the brain: an index of volume transmission mediated actions? J Neurochem 85:23-33.

Dringen R, Pfeiffer B, Hamprecht B (1999) Synthesis of the antioxidant glutathione in neurons: supply by astrocytes of CysGly as precursor for neuronal glutathione. J Neurosci 19:562-579.

Hershkovitz E, Shorer Z, Levitas A, Tal A (1996) Status epilepticus following intravenous N-acetylcysteine therapy. Isr J Med Sci 32:1102-1114.

Kaminski RM, Livingood MR, Rogawski MA (2004) Allopregnanolone analogs that positively modulate GABA receptors protect against partial seizures induced by $6-\mathrm{Hz}$ electrical stimulation in mice. Epilepsia 45:864-877.

Kaminski RM, Shippenberg TS, Witkin JM, Rocha BA (2005) Genetic deletion of the norepinephrine transporter decreases vulnerability to seizures. Neurosci Lett 382:51-55.

Kranich O, Dringen R, Sandberg M, Hamprecht B (1998) Utilization of cysteine and cysteine precursors for the synthesis of glutathione in astroglial cultures: preference for cystine. Glia 22:11-18.

Lewerenz J, Maher P (2009) Basal levels of eIF2alpha phosphorylation determine cellular antioxidant status by regulating ATF4 and xCT expression. J Biol Chem 284:1106-1115.

Liu X, Rush T, Zapata J, Lobner D (2009) Beta-N-methylamino-l-alanine induces oxidative stress and glutamate release through action on system Xc(-). Exp Neurol 217:429-433.

Massie A, Schallier A, Mertens B, Vermoesen K, Bannai S, Sato H, Smolders I, Michotte Y (2008) Time-dependent changes in striatal xCT protein expression in hemi-Parkinson rats. Neuroreport 19:1589-1592.

Massie A, Goursaud S, Schallier A, Vermoesen K, Meshul CK, Hermans E, Michotte Y (2010) Time-dependent changes in GLT-1 functioning in striatum of hemi-Parkinson rats. Neurochem Int 57:572-578.

Massie A, Schallier A, Kim SW, Fernando R, Kobayashi S, Beck H, De Bundel D, Vermoesen K, Bannai S, Smolders I, Conrad M, Plesnila N, Sato H, Michotte Y (2011) Dopaminergic neurons of system $\mathrm{x}_{\mathrm{c}}^{-}$-deficient mice are highly protected against 6-hydroxydopamine-induced toxicity. FASEB J 25:1359-1369.

Melendez RI, Vuthiganon J, Kalivas PW (2005) Regulation of extracellular glutamate in the prefrontal cortex: focus on the cystine glutamate exchanger and group I metabotropic glutamate receptors. J Pharmacol Exp Ther 314:139-147.

Murphy TH, Schnaar RL, Coyle JT (1990) Immature cortical neurons are uniquely sensitive to glutamate toxicity by inhibition of cystine uptake. FASEB J 4:1624-1633.

Patel SA, Warren BA, Rhoderick JF, Bridges RJ (2004) Differentiation of substrate and non-substrate inhibitors of transport system xc(-): an obligate exchanger of L-glutamate and L-cystine. Neuropharmacology 46:273-284.

Qin S, Colin C, Hinners I, Gervais A, Cheret C, Mallat M (2006) System Xcand apolipoprotein $\mathrm{E}$ expressed by microglia have opposite effects on the neurotoxicity of amyloid-beta peptide 1-40. J Neurosci 26:3345-3356.

Reisel D, Bannerman DM, Schmitt WB, Deacon RM, Flint J, Borchardt T, Seeburg PH, Rawlins JN (2002) Spatial memory dissociations in mice lacking GluR1. Nat Neurosci 5:868-873.

Sagara J, Miura K, Bannai S (1993) Cystine uptake and glutathione level in fetal brain cells in primary culture and in suspension. J Neurochem 61:1667-1671.

Sarnyai Z, Sibille EL, Pavlides C, Fenster RJ, McEwen BS, Toth M (2000) Impaired hippocampal-dependent learning and functional abnormalities 
in the hippocampus in mice lacking serotonin(1A) receptors. Proc Natl Acad Sci U S A 97:14731-14746.

Sarter MF, Bruno JP (1994) Cognitive functions of cortical Ach: lessons from studies on trans-synaptic modulation of activated efflux. Trends Neurosci 17:217-221.

Sato H, Tamba M, Ishii T, Bannai S (1999) Cloning and expression of a plasma membrane cystine/glutamate exchange transporter composed of two distinct proteins. J Biol Chem 247:11455-11468.

Sato H, Shiiya A, Kimata M, Maebara K, Tamba M, Sakakura Y, Makino N, Sugiyama F, Yagami K, Moriguchi T, Takahashi S, Bannai S (2005) Redox imbalance in cystine/glutamate transporter-deficient mice. J Biol Chem 280:37423-37439.

Schallier A, Smolders I, Van Dam D, Loyens E, De Deyn PP, Michotte A, Michotte Y, Massie A (2011) Region- and age-specific changes in glutamate transport in the A $\beta$ PP23 mouse model for Alzheimer's disease. J Alzheimers Dis 23:1-14.

Schmitt WB, Deacon RM, Seeburg PH, Rawlins JN, Bannerman DM (2003) A within-subjects, within-task demonstration of intact spatial reference memory and impaired spatial working memory in glutamate receptor-Adeficient mice. J Neurosci 23:3953-3969.

Sepkuty JP, Cohen AS, Eccles C, Rafiq A, Behar K, Ganel R, Coulter DA, Rothstein JD (2002) A neuronal glutamate transporter contributes to neurotransmitter GABA synthesis and epilepsy. J Neurosci 22:6372-6379.

Shanker G, Aschner M (2001) Identification and characterization of uptake systems for cystine and cysteine in cultured astrocytes and neurons: evidence for methylmercury-targeted disruption of astrocyte transport. J Neurosci Res 66:998-1002.

Shibata T, Yamada K, Watanabe M, Ikenaka K, Wada K, Tanaka K, Inoue $\mathrm{Y}$ (1997) Glutamate transporter GLAST is expressed in the radial glia-astrocyte lineage of developing mouse spinal cord. J Neurosci 17:9212-9219.

Shih AY, Johnson DA, Wong G, Kraft AD, Jiang L, Erb H, Johnson JA, Murphy TH (2003) Coordinate regulation of glutathione biosynthesis and release by Nrf2-expressing glia potently protects neurons from oxidative stress. J Neurosci 23:3394-3406.

Shih AY, Erb H, Sun X, Toda S, Kalivas PW, Murphy TH (2006) Cystine/ glutamate exchange modulates glutathione supply for neuroprotection from oxidative stress and cell proliferation. J Neurosci 26:10514-10523.

Smolders I, Lindekens H, Clinckers R, Meurs A, O’Neill MJ, Lodge D, Ebinger $\mathrm{G}$, Michotte Y (2004) In vivo modulation of extracellular hippocampal glutamate and GABA levels and limbic seizures by group I and II metabotropic glutamate receptor ligands. J Neurochem 88:1068-1077.

Sontheimer H (2003) Malignant gliomas: perverting glutamate and ion homeostasis for selective advantage. Trends Neurosci 26:543-549.

Takaki M, Ueda Y, Doi T, Nagatomo K, Murashima YL, Kannan H (2008) Molecular regulation of antioxidant ability in the hippocampus of EL mice. Brain Res 4:1228-1233.

Tian GF, Azmi H, Takano T, Xu Q, Peng W, Lin J, Oberheim N, Lou N, Wang X, Zielke HR, Kang J, Nedergaard M (2005) An astrocytic basis of epilepsy. Nat Med 11:973-981.

Ueda Y, Doi T, Takaki M, Nagatomo K, Nakajima A, Willmore LJ (2009) Levetiracetam enhances endogenous antioxidant in the hippocampus of rats: in vivo evaluation by brain microdialysis combined with ESR spectroscopy. Brain Res 17:1-7.

Van Hemelrijck A, Sarre S, Smolders I, Michotte Y (2005) Determination of amino acids associated with cerebral ischaemia in rat brain microdialysates using narrowbore liquid chromatography and fluorescence detection. J Neurosci Methods 144:63-71.

Velisek L (2006) Models of chemically-induced acute seizures. In: Models of seizures and epilepsy (Pitkanen A, Schwartzkroin PA, Moshe S, eds), pp 127-152. Burlington: Elsevier Academic.

von Lubitz DK, Paul IA, Carter M, Jacobson KA (1993) Effects of N6cyclopentyl adenosine and 8-cyclopentyl-1,3-dipropylxanthine on $\mathrm{N}$-methyl-D-aspartate induced seizures in mice. Eur J Pharmacol 249:265-270.

White HS, Smith-Yockman M, Srivastava A, Wilcox KS (2006) Therapeutic assays for the identification and characterization of antiepileptic and antiepileptogenic drugs. In: Models of seizures and epilepsy (Pitkanen A, Schwartzkroin PA, Moshe S, eds), pp 539-550. Burlington: Elsevier Academic.

Yamada K, Watanabe M, Shibata T, Nagashima M, Tanaka K, Inoue Y (1998) Glutamate transporter GLT-1 is transiently localized on growing axons of the mouse spinal cord before establishing astrocytic expression. J Neurosci 18:5706-5713. 